archives-ouvertes

\title{
Phenolamides in plants: An update on their function, regulation, and origin of their biosynthetic enzymes
}

Marwa Roumani, Sébastien Besseau, David Gagneul, Christophe Robin, Romain Larbat

\section{To cite this version:}

Marwa Roumani, Sébastien Besseau, David Gagneul, Christophe Robin, Romain Larbat. Phenolamides in plants: An update on their function, regulation, and origin of their biosynthetic enzymes. Journal of Experimental Botany, Oxford University Press (OUP), 2020, 10.1093/jxb/eraa582 . hal03066081

\section{HAL Id: hal-03066081 \\ https://hal.univ-lorraine.fr/hal-03066081}

Submitted on 15 Dec 2020

HAL is a multi-disciplinary open access archive for the deposit and dissemination of scientific research documents, whether they are published or not. The documents may come from teaching and research institutions in France or abroad, or from public or private research centers.
L'archive ouverte pluridisciplinaire HAL, est destinée au dépôt et à la diffusion de documents scientifiques de niveau recherche, publiés ou non, émanant des établissements d'enseignement et de recherche français ou étrangers, des laboratoires publics ou privés. 


\section{Phenolamides in plants: An update on their function, regulation, and origin of their biosynthetic enzymes}

Marwa Roumani ${ }^{*}$, Sébastien Besseau ${ }^{2 *}$, David Gagneul ${ }^{3}$, Christophe Robin ${ }^{1}$, Romain Larbat $^{1 \ddagger}$

${ }^{1}$ UMR 1121, Laboratoire Agronomie et Environnement (LAE), Université de LorraineINRAe, Nancy, France,

${ }^{2}$ EA 2106, Biomolécules et biotechnologies végétales (BBV), Université de Tours, Tours, France,

${ }^{3}$ UMR 1158, BioEcoAgro, Université de Lille, INRAe, Université de Liège, UPJV, YNCREA, Université d'Artois, Université Littoral Côte d'Opale, Institut Charles Viollette (ICV), Lille, France

marwa.roumani@univ-lorraine.fr

sebastien.besseau@univ-tours.fr

david.gagneul@univ-lille.fr

christophe.robin@univ-lorraine.fr

romain.larbat@univ-lorraine.fr

* These authors contributed equally to the work presented.

$\$$ Correspondence:

Romain Larbat

romain.larbat@univ-lorraine.fr

\section{Highlights:}

This paper reviews the functional aspects of phenolamides in plants, the molecular regulation of their biosynthesis in response to biotic stress, and prospects for their phylogenetic origin through classification of N-hydroxycinnamoyltransferases 


\begin{abstract}
Phenolamides represent a family of specialized metabolites, consisting of the association of hydroxycinnamic acid derivatives with aliphatic or aromatic amines. Since the discovery of the first phenolamide in the late 1940's, decades of phytochemical analyses have revealed a high structural diversity for this family and a wide distribution in the plant kingdom. The occurrence of structurally diverse phenolamides in almost all plant organs has led to early hypotheses on their involvement in floral initiation and fertility, as well as plant defense against biotic and abiotic stress. In the present work, we critically review literature ascribing functional hypotheses to phenolamides and recent evidence on the control of their biosynthesis in response to biotic stress. We additionally provide a phylogenetic analysis of the numerous $\mathrm{N}$-hydroxycinnamoyltransferases involved in the synthesis of phenolamides and discuss the potential role of other enzyme families in their diversification. The data presented suggests multiple evolutionary events that contributed to the extension of the taxonomic distribution and diversity of phenolamides.
\end{abstract}

Keywords: bioactivity, phenolamides, plant defense, plant reproduction, phylogenesis. 


\section{Introduction}

Specialized metabolism continuously expands during evolution of the green lineage. This has generated an enormous chemodiversity, largely responsible for the tremendous adaptability of plants to their challenging environment. Specialized metabolites arising from this metabolism provide plants with a plethora of molecules that allow their interaction (defense, protection, or attraction) with their abiotic (UV, temperature, and water deficit, among others) or biotic (pathogens and insects, among others) environments. Among these compounds, phenolamides, also termed hydroxycinnamic acid amides or phenylamides, have generated considerable attention recently. Phenolamides arise from phenolic moieties (mainly hydroxycinnamic acids and derivatives) covalently linked through amide bonds to an aromatic monoamine or an aliphatic polyamine (e.g. tyramine, agmatine, anthranilate, spermidine). Therefore, these phenolic compounds can be considered alkaloids. Their synthesis is positioned at the crossroads of the phenylpropanoid pathway and the metabolism of amines (Bassard et al., 2010) (Fig. 1; Sup. Fig. 1).

Feruloylputrescine was the first phenolamide identified in the middle of the twentieth century (Ryabinine and Ilina, 1949). Since then, a plethora of structures have been elucidated (Fig. 1; Sup. Fig. 1) and theoretical phenolamide diversity could reach more than 5000 compounds. Phenolamides have been described throughout the plant kingdom and they accumulate in various organs, sometimes at very high concentrations, especially in wounded tissues (Roepenack-Lahaye et al., 2003; Zacarés et al., 2007; Kaur et al., 2010; Onkokesung et al., 2012), at the surface of pollen grains, in flowers, and in seeds (Meurer et al., 1998; Grienenberger et al., 2009; Luo et al., 2009; Vogt, 2018). Although phenolamide structure and distribution are now well documented (Martin-Tanguy et al., 1978; Luo et al., 2009; Kaur et al., 2010; Dong et al., 2015), their physiological or biological roles are still poorly understood. Their implication in plant defense against pathogens and herbivores has been suggested and sometimes demonstrated (Zacarés et al., 2007; Kaur et al., 2010; López-Gresa et al., 2010; Alamgir et al., 2016). However, no clear function is associated with their presence in large amounts in floral organs and the pollen coat (Fellenberg et al., 2009; Grienenberger et al., 2009; Vogt, 2018). Concomitant with the discovery of phenolamide diversity, characterization of N-hydroxycinnamoyltransferases involved in their synthesis highlighted the complexity of phenolamide appearance in the green lineage, resulting from numerous and independent gene emergence. This gave clues to explain the origins of structures, their diversity, and species/organ specificity of phenolamides (Bassard et al., 2010; Elejalde-Palmett et al., 2015).

A review of the literature on phenolamides reveals three main periods of research conducted on these molecules (Fig. 2). From 1949 to 2007, the structure of the first major phenolamides was elucidated, and the enzymes involved in their synthesis were identified as a new type of enzyme with N-hydroxycinnamoyltransferase activity. Their roles have been hypothesized in development and flowering, as well as in the defense of the plant against abiotic stress, injury, and pathogen attack. This period was the subject of two main reviews (Facchini et al., 2002; Edreva et al., 2007). The second period (2007 to 2015) was marked by an increase in the number of phenolamide structures reported due to the democratization and improvement 
of instrumental tools for phytochemical analysis, by proof of their role in defense against insects and by the discovery of genes encoding new enzymes, including spermidine and putrescine N-hydroxycinnamoyltransferases. The first elements of their synthesis regulation were compiled in the review of Bassard et al. (2010). Since then, so called 'omic' approaches have been applied to phenolamides and more plant species have been investigated ( $\mathrm{Li}$ et al., 2018). Phenolamide accumulation appears as a conserved chemical trait in the pollen coat of core Eudicotyledons, suggesting an important role of these molecules in pollen biology. The acquisition of transcriptomic data in different non model or model plants has made it possible to explore phenolamide biosynthesis enzyme phylogenesis and help $\mathrm{N}$ hydroxycinnamoyltransferase orthologue identification among plant species, increasing the number of characterized enzymes from 21 to 43. Concomitantly, major advances have been made on the regulation of their biosynthesis in response to biological aggressors (Onkokesung et al., 2012; Yogendra et al., 2015, 2017; Schäfer et al., 2015; Fagin et al., 2020).

From this founding work and the most recent research, we describe the newly discovered occurrence of phenolamide diversity in reproductive organs and their possible functions in reproduction. The defensive role of phenolamides in response to biotic and abiotic stress is then described with an emphasis on the regulation of their biosynthesis and their specific role. In the last part of the review, we describe the enzymes involved in the metabolism of phenolamides and explore the origin of $\mathrm{N}$-hydroxycinnamoyltransferases. Chemistry, biotechnological production, and health benefits of phenolamides were not detailed here as two recent reviews already summarized these aspects (Wang et al., 2020; Roumani et al., 2020).

\section{Biological roles of phenolamides}

\subsection{Role in reproduction}

\subsubsection{Phenolamides in relation to floral initiation and flower fertility}

Mono- and di-putrescine, spermidine and spermine phenolamides are considered to be involved in plant development and, like free polyamines, could behave as plant growth regulators (Tiburcio et al., 1993; Martin-Tanguy, 1997; Edreva et al., 2007). Indeed, several studies indicate that their relative contents are closely related to biological processes, such as cell proliferation, callus formation, cell differentiation, embryogenesis, or organogenesis (Edreva et al., 2007). Nevertheless, these findings often rely on correlations and no direct evidence was provided until now. A link between floral initiation, flower fertility, and phenolamide accumulation was established decades ago, but molecular evidence was missing. In several plant families, such as Solanaceae, Brassicaceae, Asteraceae, and Araceae, the accumulation of phenolamides to a high level in the upper leaves and apices appears to precede floral initiation (Cabanne et al., 1981; Martin-Tanguy, 1985; MartinTanguy, 1997). Consistently, mutant plants that fail to flower do not accumulate phenolamides (Martin-Tanguy, 1985). In addition, the accumulation of phenolamides seems to be linked to flower fertility (Bassard et al., 2010). In Brassica juncea, the level of soluble and insoluble phenolamides (derived from mono and di-substituted putrescine, spermidine, or 
spermine) was shown to be lower in cytoplasmic male sterile plants than in the wild-type plants during flower development, which is consistent with a putative role in fertility (Guo et al., 2003). Phenolamides could act as ROS scavenging molecules, among other, during flower development, thus, preventing oxidative damage, leading to pollen abortion in cytoplasmic male sterile plants, as suggested in soybean (Ding et al., 2019).

\subsubsection{Phenolamides in the pollen coat of Eudicotyledons}

The pollen cell wall is very sophisticated and complex. The mature pollen grain is generally composed of three layers. The inner part of the pollen cell wall, known as the intine, is synthesized by the microspores themselves, while the outer part, called the exine, is produced by the surrounding sporophytic tapetal cells and deposited on the surface of the maturating pollen grain within the locules of the anthers (Hess, 1993; Ariizumi and Toriyama, 2011). While the intine ensures pollen structural integrity during pollen maturation, the exine encapsulates and sculpts the pollen grain, providing mechanical and chemical protection and playing a role in the pollen-stigma interaction. In most species, the pollen grain is additionally covered by another layer called the pollen coat or tryphine. Constituting the most outer part of the pollen grain, the pollen coat plays a role in multiple mechanisms, such as pollen-stigma recognition, self-incompatibility, pollen adhesion to pollinators, protection against abiotic and biotic stress, and pollen hydration. Like the exine, precursors required for the formation of the pollen coat originate from the tapetal cells. The chemical composition of the pollen coat is highly variable among species, but a common feature is the accumulation of phenolamides (Grienenberger et al., 2009; Quilichini et al., 2015). They are accumulated in the pollen coat of nearly all core Eudicotyledons (Elejalde-Palmett et al., 2015; Delporte et al., 2018). They are absent in the pollen wall of Gymnosperms, and only one Monocotyledon, Canna indica, was shown to accumulate such compounds, although at trace levels (ElejaldePalmett et al., 2015). This chemical trait was described several decades ago but more detailed analyses have been undergone recently, notably, through the characterization of the molecular determinants responsible for their accumulation as discussed below (ElejaldePalmett et al., 2015; Delporte et al., 2018). Particularities of these phenolamides are that they are derived from aliphatic polyamines and are fully substituted, i.e. primary and secondary amines are acylated. Until recently, trihydroxycinnamoyl spermidines were considered a unique marker of the pollen coat of Eudicotyledons (Elejalde-Palmett et al., 2015). As a constituent of the pollen coat, trihydroxycinnamoyl spermidines were shown to be produced in the tapetal cells and deposited on the outer surface of the pollen grain (Grienenberger et al., 2009; Elejalde-Palmett et al., 2015). The decoration of spermidine varies between species, i.e. aromatic moiety of the phenolics can differ (from $p$-coumaroyl to sinapoyl, see Fig. 1 and Sup. Fig. 1 for a list). For example, in Arabidopsis, two main phenolamides were shown to accumulate in the pollen coat, i.e. tri(5-hydroxyferuloyl) spermidine and di(5hydroxyferuloyl)-sinapoylspermidine, whereas in apple trees, tricoumaroyl spermidine and dicoumaroyl-caffeoylspermidine were the main molecules (Grienenberger et al., 2009; Elejalde-Palmett et al., 2015). Nevertheless, very recently, Delporte et al., (2018) showed that, in the Asteraceae family, fully substituted spermine derivatives were the main phenolamide accumulated in the pollen coat. In the species of this family, spermidine derivatives were present but at a lower concentration. The acylation pattern of spermine can 
vary, depending on the species, in this family. Spermine could be acylated with $p$-coumaric and/or caffeic acid (Delporte et al., 2018). For instance, N', N', N',' N',', tetracoumaroylspermine was accumulated in chicory. This study showed that fully substituted aliphatic polyamines are indeed a marker of the Eudicotyledons, but fully substituted spermine derivatives are markers of the pollen of the Asteraceae family (Delporte et al., 2018).

The role of the fully substituted phenolamides derived either from spermidine or spermine is still under debate, and because they are restricted to the pollen coat, they are often considered separately from the other phenolamides (Fellenberg and Vogt, 2015; Vogt, 2018). The fact that their accumulation in the pollen coat is a chemical trait preserved during the evolution of the green lineage suggests that they must play a role of paramount importance. The occurrence of spermine derivatives in replacement of spermidine derivatives in Asteraceae is also intriguing and deserves attention. This metabolic diversification may reflect an evolutionary advantage that still needs to be uncovered (Delporte et al., 2018). In the Arabidopsis mutant Atsht, where phenolamides are totally absent in the pollen coat, no clear phenotype was highlighted (Grienenberger et al., 2009). The pollen morphology was slightly altered, suggesting a role in sporopollenin ultrastructure, but the pollen grain was still viable and fertile (Grienenberger et al., 2009). Because of the hydroxycinnamoyl spermidine absorption spectra, they were predicted to be involved in UV protection. Nevertheless, pollen grains depleted in spermidine derivatives isolated from Atsht mutants did not show any impairment of their ability to germinate or to grow a pollen tube in vitro, as well as in vivo (Grienenberger et al., 2009). The effects of UV irradiation have not been examined at the DNA level. It is possible that phenolamides have a role in protecting genetic information inherited by offspring. This may explain why their accumulation in the pollen coat was maintained through evolution of the green lineage. Further experiments are needed to test this hypothesis. A role of phenolamides in the control of polyamine homeostasis was suggested (Fellenberg et al., 2012). Indeed, polyamines are involved in multiple physiological processes and their intracellular pools need to be finely tuned through compartmentation, control of their synthesis (transcriptional and translational regulation) and degradation, and eventually through conjugation (Bouchereau et al., 1999). Nevertheless, analysis of the Atsht mutant showed no alteration of free polyamine levels (Fellenberg et al., 2012). Experiments done in vitro with phenolamides extracted and partially purified from bee pollen evidenced the putative role of these molecules in oxidative stress protection (Zhang et al., 2020). Additionally, some antifungal properties were also reported for phenolamides accumulated at the surface of sunflower pollen (Kyselka et al., 2018). In addition, by comparison to phenolamides accumulated in other parts of the plant (see below), multiple roles have been tentatively assigned to their accumulation in the pollen coat, such as protection against abiotic or biotic stress (desiccation resistance, antifungal activity, insect interaction, antimicrobial activity), function in the stigma-pollen interaction, and pollen germination (Grienenberger et al., 2009; Elejalde-Palmett et al., 2015; Fellenberg and Vogt, 2015; Delporte et al., 2018; Vogt, 2018). Notably, Arabidopsis is a self-pollinated species and its pollen is not exposed to harsh environments. Studies with other species may help to solve this question. With the 
emergence of new genome editing methods, mutants of other crop species may become available to test these hypotheses.

\subsection{Protective roles against biotic stresses}

\subsubsection{Pathogens}

Since the first demonstration of $p$-coumaroyl- and feruloyl-2-hydroxyputrescine accumulation in leaves of rust-infected wheat (Samborski and Rohringer, 1970), multiple studies on Solanaceae, Brassicaceae, and Poaceae confirmed that phenolamide accumulation in response to microbial infection is a global trend (Negrel and Jeandet, 1987; Torrigiani et al., 1997; Roepenack-Lahaye et al., 2003; King and Calhoun, 2005; Zacarés et al., 2007; Muroi et al., 2009; Lopez-Gresa et al., 2016; Royer et al., 2016; Morimoto et al., 2018; Ube et al., 2019a,b). Except for tri-substituted spermine derivatives, all classes of phenolamides appear to be involved in these interactions. However, no clear rule has been identified linking the nature of the induced phenolamide to the nature of the pathogen or plant species (Roepenack-Lahaye et al., 2003; Baker et al., 2005; Zacarés et al., 2007; Royer et al., 2016; Novo et al., 2017; Morimoto et al., 2018; Ube et al., 2019a). The study of mutants or engineered plants affected in phenolamide biosynthesis highlighted that phenolamides are an effective component of the plant defense strategy against pathogens. Indeed, potato plants with silenced transcription factors StNAC43, StMYB8, and StWRKY1 accumulated less phenolamides and were more susceptible to Phytophtora infestans (Yogendra et al., 2015, 2017). An increased susceptibility to Alternaria brassicicola was also observed in Arabidopsis mutant Atact, which were depleted in p-coumaroylagmatine (Muroi et al., 2009). In contrast, overexpression of endogenous Tyramine Hydroxycinnamoyl Transferase (THT) in tomato increased accumulation of tyramine and octopamine derivatives and its resistance to Pseudomonas syringae (Campos et al., 2014), whereas the ectopic expression of the Arabidopsis Agmatine coumaroyl transferase (AtACT) in torenia plants rendered them more resistant to Botrytis cinerea (Muroi et al., 2012). Potato plants overexpressing both AtACT and the Arabidopsis DETOXIFICATION18 (AtDTX18) gene gained the capacity to synthesize $p$-coumaroylagmatine and export it to the leaf surface. Interestingly, the enhanced accumulation of $p$-coumaroylagmatine, $p$-coumaroyl-, and caffeoylputrescine on the potato leaf surface reduced spore germination of $P$. infestans (Dobritzsch et al., 2016).

The protective role of phenolamides against microbes involves at least two processes: direct antimicrobial activity and reinforcement of the secondary cell wall. Their antimicrobial activity has been demonstrated against bacteria and fungi, mostly through in vitro assays. Tyramine- and tryptamine-based phenolamides exhibit growth inhibition activity against Xanthomonas sp. (Newman et al., 2001; Morimoto et al., 2018), whereas pcoumaroylnoradrenaline together with $p$-coumaroyldopamine and feruloyldopamine are particularly effective in inhibiting the growth of $P$. syringae (Roepenack-Lahaye et al., 2003; Zacarés et al., 2007). Regarding antifungal activities, hordatines (hydroxycinnamoylagmatine dimers) were shown to inhibit the spore germination of 6 fungi, including Bipolaris sorokiniana and Botrytis allii, at low concentrations (as low as $10^{-5} \mathrm{M}$ ) (Stoessl and Unwin, 1970). Two agmatine-based phenolamides from barley, murinamides $A$ and B, were recently characterized for their capacity to inhibit spore germination and germ tube elongation of $B$. 
sorokiniana, Fusarium graminearum, and A. brassicicola (Ube et al., 2017). An antifungal effect impacting both spore germination and hyphal elongation was also demonstrated for $p$ coumaroylagmatine on A. brassicicola (Muroi et al., 2009). More recently, several phenolamides arising from tryptamine, serotonine, and tyramine were described to inhibit the conidial germination of the pathogenic fungus Cochliobolus miyabeanus (Morimoto et al., 2018). Phenolamides also contribute to reinforce the secondary cell wall upon pathogen infection, commonly named suberization. Indeed, involvement of tyramine associated phenolamides in the suberization process was demonstrated decades ago by a set of studies combining ${ }^{14} \mathrm{C}$ labelling and substructure cell fractionation on wounded or fungus-infected potato leaves and cell cultures (Negrel and Jeandet, 1987; Schmidt et al., 1998). Phenolamide integration in the cell wall was also reported in fungal-infected barley ( $p$ coumaroylhydroxyagmatine), in chitin-elicited oat (avenanthramide), in virus-infected tobacco (feruloylputrescine and feruloyltryptamine), and fungus-infected potato plants (Torrigiani et al., 1997; Yogendra and Kushalappa, 2016). Incorporation to the secondary cell wall appears as a multistep process involving phenolamide dimerization or polymerization, which could necessitate peroxidase activity, followed by integration to the cell wall (King and Calhoun, 2005). The consequence of phenolamide incorporation to the cell wall is the reduction of its digestibility by pathogen hydrolytic enzymes, preventing pathogen proliferation.

\subsubsection{Insects}

Phenolamide induction in response to insects has already been reported in a diversity of plants, including Solanaceae and Poaceae, by different herbivore feeding guilds, including both chewing and sucking insects (Pearce et al., 1998; Kaur et al., 2010; Alamgir et al., 2016). Among the accumulated phenolamides, putrescine and spermidine derivatives are the most frequently reported. The accumulation of tyramine derivatives was also observed in maize infested by the chewing larvae of Spodoptera littorallis (Marti et al., 2013).

The involvement of phenolamides in plant defense against insects is supported by various studies. In Nicotiana attenuata, silencing of NaMYB8 led to plants depleted in caffeoyl putrescine and dicaffeoylspermidine, on which both specialist and generalist caterpillars (Manduca sexta and S. littoralis, respectively) performed better (Kaur et al., 2010). In addition, spraying caffeoyl putrescine on leaves of silenced NaMYB8 plants reduced the mass gain of M. sexta larva (Kaur et al., 2010). Moreover, the addition of phenolamides to the artificial diet of Nilaparvata lugens and Sogatella furcifera increased their mortality (Alamgir et al., 2016). Phenolamide can also act as an oviposition decreasing factor. Sweet pepper tissues accumulating caffeoylputrescine showed ovipositional deterrence of Liriomyza trifolii leafminer, and cotyledon treatment with synthetic $p$-coumaroylputrescine also decreased oviposition (Tebayashi et al., 2007). Nevertheless, the induction of phenolamide accumulation upon herbivory is not always related to enhanced plant protection. In rice, the accumulation of $p$-coumaroyl- and feruloylputrescine appeared to have no impact on the performance of chewing insects Spodoptera mauritia and Parnara guttata (Alamgir et al., 2016). Moreover, in maize, the induced accumulation of $p$-coumaroyltyramine in response to S. littoralis herbivory appeared to benefit larvae development. Indeed, in vitro observations 
showed that $p$-coumaroyltyramine present in the diet is beneficial for larval growth (Marti et al., 2013). In $N$. attenuata, the accumulation of the mixture of phenolamides upon attacks suggested that various phenolamides are required to maximize defense efficiency (Onkokesung et al., 2012).

\subsection{Protective role against abiotic stress}

Studies on phenolamides related to abiotic stress are rarer and less detailed than those related to biotic stress. Phenolamide accumulation has been reported in several plants in response to a large range of abiotic stress. Mineral deficiencies $(\mathrm{K}, \mathrm{Ca}, \mathrm{Mg}, \mathrm{P}, \mathrm{S}$, and $\mathrm{Cu}$ ), high temperatures, water excess, and exposure to UV-B and short-term acute $\mathrm{O}_{3}$ levels induced putrescine and spermidine derivative accumulation in wheat, as well as in tobacco plant and cell cultures (Klapheck, 1983; Edreva et al., 1995; Edreva et al., 1998; Königshofer and Lechner, 2002; Demkura et al., 2010). Wounding induced the accumulation of tyramine, octopamine, and putrescine derivatives in potato and tomato plants (Negrel et al., 1996; Pearce et al., 1998; Matsuda et al., 2005).

A few studies demonstrated the negative impact of abiotic factors on phenolamide accumulation. This is the case with salt stress and nitrogen limitation (Shevyakova et al., 2006; Larbat et al., 2014). In the latter case, since nitrogen limitation promotes an increase in the concentration of phenolic compounds, the impact on phenolamide accumulation may be the consequence of a down-regulation in phenolamide specific acyltransferases or of a decrease in polyamine concentration.

Recently long-term disturbance of abiotic factors involved in climate change (elevation of $\mathrm{CO}_{2}$ and $\mathrm{O}_{3}$ concentrations and temperature) have been evaluated on constitutive and pathogen-induced leaf specialized metabolites in barley. Plants grown under high temperature conditions $\left(+5^{\circ} \mathrm{C}\right)$ accumulated more hordatine in non-infected leaves, but also more agmatine derivatives after pathogen infection. The impact of abiotic factors was, however, very specific to phenolamides (Mikkelsen et al., 2015).

The exact role of phenolamide accumulation on plant adaptation to abiotic stress is still a matter of hypotheses that need to be validated. One of them is that phenolamides contribute to limit the oxidative burst mediated by various abiotic stressors. Phenolamides are effective free radical scavengers and antioxidants (Langebartels et al., 1991; Edreva et al., 1998; Choi et al. 2007; Georgiev et al. 2012; Abe et al., 2017). Regarding the increase of phenolamides under UV treatment and the phenotype of $N$. attenuata lacking phenolamides under UV, it seems that they may also be involved in plant protection against solar UV. The mechanism of action still needs to be determined, but the role in UV absorbance may be postulated.

\section{Regulatory aspects}

Regulatory mechanisms underlying phenolamide accumulation in response to biotic stress have been highlighted recently (Fig. 3). Regarding microbial infection, a first report on tomato defense response to $P$. syringae, demonstrated, through the use of signaling mutants and phytohormone inhibitors, that phenolamide accumulation was dependent on ethylene (ET) but not salicylic acid (SA) (Zacarés et al., 2007). The ethylene pathway, together with the jasmonate (JA) pathway, is involved in phenolamide accumulation induced by 
necrotrophic fungi A. brassicicola and B. cinerea in A. thaliana (Muroi et al., 2009; Li et al., 2018). Indeed, both phytohormones synergistically induce the expression of AtACT (Fig. 3). This induction is mediated by the transcription factor AtORA59, which is conformed as a homodimer, and when associated with the regulator MEDIATOR 25, can bind the AtACT promoter and induce its expression ( $\mathrm{Li}$ et al., 2018). Interestingly, AtACT induction is also associated with the expression of DTX18, a Multidrug And Toxin Extrusion (MATE) transporter initially found to export $p$-coumaroylagmatine on the surface of Arabidopsis leaves when challenged with the non-hosted fungus $P$. infestans, the causal agent of the late blight in potato (Dobritzsch et al., 2016). An exhaustive analysis of the potato defense response in resistant and sensible cultivars infested with $P$. infestans led to the identification of at least two complementary pathways regulating the accumulation of phenolamides that occur in resistant cultivars (Yogendra et al., 2015, 2017). A first pathway is initiated by ET and involves a cascade of transcription factor regulation, including StERF3, which activates the transcription of $S t$ NAC43 that, in turn, activates StMYB8 expression (Fig. 3). StMYB8 is a transcription factor that positively regulates the expression of a subset of genes involved in the phenylpropanoid pathway. Among them, hydroxycinnamoyl-CoA:shikimate/quinate hydroxycinnamoyl transferase (HCT) and putrescine N-hydroxycinnamoyl transferase (PHT) are related to the metabolism of phenolamides, and others are related to the accumulation of flavonoids. Interestingly, silencing of either StNAC43 or StMYB8 impairs the accumulation of phenolamides and flavonoids and reduces the potatoes' resistance to $P$. infestans (Yogendra et al., 2017). A second pathway involves the transcription factor StWRKY1 (Fig. 3). StWRKY1 activity could be regulated at the transcription level, since binding sites to Heat Shock Protein (HSP) have been found in its promoter, or at the protein level through phosphorylation by StMEK1, a MAP kinase, which could enable the migration of StWRKY1 into the nucleus (Yogendra et al., 2015). Interestingly, the two regulation pathways highlighted in potato appear to control different phenolamide subsets; the former one being more focused on putrescine and agmatine derivatives and the latter one involving tyramine and octopamine derivatives (Yogendra et al., 2015, 2017). In wheat, another WRKY

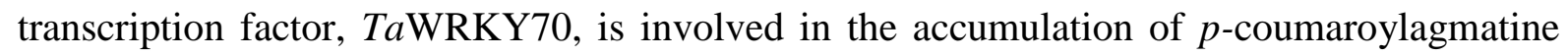
and $p$-coumaroylputrescine in response to infection with $F$. graminearum (Kage et al., 2017).

The mechanisms regulating the accumulation of caffeoylputrescine and mono- and dicaffeoylspermidine in response to herbivory have been extensively studied on the solanaceous model $N$. attenuata. The accumulation of phenolamides, together with nicotine and trypsin protease inhibitor accumulations, constitutes the main response of this plant to herbivory attacks (Gaquerel et al., 2014). Cumulative data including studies on mutants and transformants impaired in jasmonate biosynthesis and signaling, demonstrated that herbivoreinduced phenolamide accumulation is mediated by the JA pathway and identified major steps of this pathway (Halitschke and Baldwin, 2003; Paschold et al., 2007; Stitz et al., 2011) (Fig. 3). Downstream of the JA pathway, the transcription factor NaMYB8 appears as a master regulator, positively controlling the expression level of genes involved in the phenylpropanoid pathway (PAL, C4H) and genes encoding transferases (NaAT1, NaDH29, $\mathrm{NaCV86)}$ that catalyze the final steps of caffeoylputrescine and dicaffeoylspermidine synthesis (Kaur et al., 2010; Onkokesung et al., 2012). This classical JA-mediated response to 
herbivores can be modulated by a huge number of regulatory processes. Among them, phytohormone crosstalk constitutes a major regulator. Indeed, herbivory was proven to induce bursts of several phytohormones, such as SA and cytokinin (CYT), in addition to JA (Fig. 3). SA and JA are well known antagonist phytohormones that promote the defense response to pathogens and herbivores, respectively. In response to herbivores, the antagonistic impact of SA on JA can be negated by regulatory proteins, including NPR1 (Rayapuram and Baldwin, 2007). CYT appears as a positive modulator of the JA-dependent response to herbivores since $N$. attenuata plants affected by CYT perception develop a lower phenolamide accumulation in response to herbivores (Schäfer et al., 2015). Interestingly, CYT and the auxin indole acetic acid (IAA) are important for constitutive phenolamide response to herbivores (Schäfer et al., 2015), whereas ET was recently proved as an attenuator of locally-induced phenolamide accumulation (Fagin et al., 2020). In rice, the auxin homolog 2,4-dichlorophenoxyacetic acid (2,4-D) stimulates the JA-dependent response to herbivores (Xin et al., 2012).

Phenolamide induction in response to herbivores is also modulated by small RNAs. In the case of $N$. attenuata, the small RNA machinery involves the proteins RNA-directed RNA polymerase 1 (RdR1), Dicer-like DCL3 and DCL4, and Argonaute 8 (AGO8) (Pandey and Baldwin, 2007; Bozorov et al., 2012; Pradhan et al., 2017). The mechanisms by which this complex modulates herbivore-induced phenolamide accumulation are still unclear. Interestingly, the herbivore-induced phenolamide response is also modulated by abiotic stress, such as UV-B, which also stimulate the JA pathway (Demkura et al., 2010).

Behind the extensive knowledge acquired on the model plant $N$. attenuata, mechanistic insights on herbivore-induced phenolamides are much more limited. In $N$. tabacum cell cultures, phenolamide response to Methyl-Jasmonate (MeJA) treatment is mediated by the transcription factor NtMYBJS1, a close NaMYB8 ortholog (Gális et al., 2006). Caffeoylputrescine content in pepper plants was increased by spraying leaves with MeJA (Tebayashi et al., 2007), and phenolamide accumulation was impaired in tomato mutants jail affected in JA perception (Chen et al., 2006). In rice, the addition of JA to seedling culture medium, increase the concentration of a wide diversity of phenolamides (Morimoto et al., 2018). However, the mutant Osjarl, deficient in JA-Ileu, was only partially affected for herbivore-induced phenolamide accumulation, suggesting an alternative regulating pathway (Tanabe et al., 2016). Further studies are needed to elucidate the regulation steps involved in diverse plant families inducing phenolamide synthesis in response to herbivores.

\section{Origin and evolution of phenolamide metabolism}

The synthesis of phenolamides involves $\mathrm{N}$-hydroxycinnamoyltransferase at the entry point of the pathway, which uses preexisting precursors as substrates derived from amine and phenylpropanoid metabolism (Fig. 1). These enzymes, specific to higher plants, catalyze the transfer of an activated hydroxycinnamoyl moiety, i.e hydroxycinnamoyl-CoA, to the amino group of an acceptor. N-hydroxycinnamoyltransferase acyl acceptor specificity is restricted to a single amine or a few related amines among polyamines (putrescine, spermidine, spermine, agmatine) or aromatic amines (tyramine, dopamine, tryptamine, serotonin, anthranilates) (Fig. 1). Besides, each N-hydroxycinnamoyltransferase uses, with various efficiency, a broad 
range of hydroxycinnamoyl and related moieties (eg. p-coumaroyl, caffeoyl, feruloyl, benzoyl), leading to a large diversity of acyl decorations on amines. Consequently, Nhydroxycinnamoyltransferase acyl donor affinity mainly defines the final product decoration, also based on the pool of endogenous hydroxycinnamic acids available.

Since the first N-hydroxycinnamoyltransferases were isolated in tobacco in 1984, a great diversity of enzymes were discovered in terms of substrate specificity (mainly amine acceptor preference), category and number of amino group acylated on acceptors (primary/secondary amino groups, mono/poly acylation), distribution within plants (constitutive expression in various organs or induction), and distribution among species. This diversity is detailed in Table 1, which summarizes the main features of the 43 N-hydroxycinnamoyltransferases isolated and biochemically characterized to date. The diversity among Nhydroxycinnamoyltransferase seems to originate from active and recent evolution mechanisms, which are, in turn, responsible for the large variety of phenolamide structures and functions, as illustrated in previous parts of the review. The elucidation of the Nhydroxycinnamoyltransferase phylogeny and evolutionary origins is important to take a step forward in knowledge on phenolamides and might facilitate further studies on enzyme identification, phenolamide distribution among plant species, and identification of universal functions. Therefore, rather than describing every characterized Nhydroxycinnamoyltransferase (Table 1), we chose to examine the phylogeny of the enzymes in this part of the review.

$\mathrm{N}$-hydroxycinnamoyltransferases originate from two distinct acyltransferase families. Most of them are classified within the plant-specific BAHD acyltransferases superfamily, whereas few are homologs to the GNAT (Gen5-related N-acetyltransferases) acyltransferase superfamily (Fig. 4). BAHD acyltransferases constitute a plant-specific group of acyltransferases, catalyzing $\mathrm{O}$-acylation or $\mathrm{N}$-acylation in an acyl-CoA dependent manner for a large diversity of acceptors. This family is named after the four enzymes that were first characterized (BEAT, ACT, HCBT, DAT). BAHD acyltransferases are mainly involved in the metabolism of flavonoids, alkaloids, hydroxycinnamic esters, long-chain fatty acids, and phenolamides (D'Auria, 2006; Tuominen et al., 2011). Enzymes belonging to this superfamily share two consensus motifs, HxxxDG and DFGWG, involved in substrate binding and catalytic activity, respectively. This family is subdivided into eight distinct clades according to sequence similarity (Fig. 4) (D'Auria, 2006; Tuominen et al., 2011). However, members of these clades exhibit very high versatile catalytic specificities, and $\mathrm{N}$ hydroxycinnamoyltransferase are diversely distributed within BAHD clades as illustrated in the phylogenic tree of Figure 3. Contrastingly, the GNAT superfamily contains Nacyltransferases found in all living organisms and is one of the largest enzyme families. These enzymes acylate the amino group of various molecules, such as aminoglycosides, histones, arylalkylamines, decarboxylated amino acid, or polyamines (Salah Ud-Din et al., 2016; Vetting et al., 2005). GNAT enzymes have highly divergent sequences but share a structural conformation, including five $\beta$-strand, three $\alpha$-helix, and a P-loop (Zhu et al. 2006). The GNAT superfamily is composed of 17 acyltransferase families involved in a large variety of functions. Among them, the DAT family, also called the SSAT family (Diamine N- 
AcylTransferase or Spermidine/Spermine N1-AcylTransferase), is dedicated to polyamine acetylation in both animals and plants (Pegg, 2008; Lou et al., 2016), but few members in plants are able to catalyze hydroxycinnamoylation (Facchini et al., 2002).

Thus, according to the phylogeny, N-hydroxycinnamoyltransferases are distributed in nine different clusters (Fig. 4). Each cluster contains enzymes that share almost the same substrate specificities and catalytic properties. We chose to attribute as cluster names, the name of the first enzymes discovered (StTHT, HvACT, AtACT1, DcHCBT, AsHHT1, NaDH29, AtSDT, Os 12g27220, and AtSHT). Clusters of BAHD N-hydroxycinnamoyltransferase probably emerged independently from canonical O-acyltransferases of the different clades, through duplication events and neo-functionalization. Slight mutations on a duplicated copy of the ancestral gene might affect the binding domain of the enzyme and lead to changes in substrate affinity and new compound synthesis. This metabolic diversification was then further maintained and expensed, depending on the positive attributes of the organism. This phenomenon has been suggested for the emergence of rosmarinic acid synthase (RAS) and spermidine hydroxycinnamoyl transferase (SHT) in BAHD clade Vb from the ancestral HCT (Petersen et al., 2009; Elejalde-Palmett et al., 2015). The independent emergence of $\mathrm{N}$ hydroxycinnamoyltransferase clusters results in a poorly conserved motif among enzymes between clusters and generates overlapping activities corresponding to convergent evolution phenomena (Peng et al., 2016). Finally, it can be assumed that the emergence of the 9 clusters occurs in a different timeline during evolution and leads to the complex distribution and synthesis regulation of phenolamides observed among plant species. To elucidate the profile of ancestral N-hydroxycinnamoyltransferase for each cluster and identify the ancestral species in which they emerged, putative orthologs among Tracheophyta belonging to every cluster were retrieved from databases and analyzed (Fig. 5 and Sup. Fig. 2).

\subsection{Cluster $S t$ THT}

The first N-hydroxycinnamoyltransferase was described in tobacco leaves challenged with tobacco mosaic virus (Negrel and Martin, 1984). The enzyme uses tyramine as the preferred acceptor substrate and has been called Tyramine Hydroxycinnamoyl Transferase (THT). Thus far, THTs have been purified in several Solanaceae (Hohlfeld et al., 1995; Negrel and Javelle, 1997) and further cloned in tobacco, tomato, potato, and pepper, forming the StTHT cluster (Schmidt et al., 1998; Farmer et al., 1999; Roepenack-Lahaye et al., 2003; Kang et al., 2009). This cluster is the only one belonging to the GNAT superfamily (Fig. 4). THT probably emerged from DAT-like enzymes involved in polyamine acetylation, such as AtNATA1 (Lou et al., 2016), and occurred in the common Solanales ancestral organism, as phylogeny analysis did not report orthologues outside this plant order (Fig. 5). Since emergence, further gene duplications occurred, leading to multiple isoforms (Farmer et al., 1999; Roepenack-Lahaye et al., 2003; Kang et al., 2009). All THTs characterized to date are able to use tyramine as an acceptor, which seems to be the original acyl acceptor of canonical THT but also use additional decarboxylated amino acid with slight divergence: octopamine for StTHT, NtTHT10/30, and NtTHT4/11; noradrenaline, dopamine, and octopamine for SlTHT1-3, SlTHT7-1, and SlTHT7-8; and serotonin for CaSHT (Schmidt et al., 1998; Roepenack-Lahaye et al., 2003; Kang et al., 2009). Most THTs are characterized by their 
expression inducibility upon several environmental challenges, such as StTHT, NtTHT10/30, NtTHT4/11, SlTHT1-3, and CaSHT. This supports the possible role of tyramine, serotonin, octopamine, noradrenaline, and dopamine based phenolamides in plant defense against biotic and abiotic stress in Solanaceae (Schmidt et al., 1998; Farmer et al., 1999; RoepenackLahaye et al., 2003; Kang et al., 2009).

\subsection{Cluster HvACT}

Agmatine hydroxyCinnamoylTransferase from barley (HvACT) is one of the first four BAHDs characterized (Burhenne et al., 2003), establishing BAHD clade IV. This clade is only composed of N-hydroxycinnamoyltransferases (Fig. 4). Cluster HvACT was initially reported to have emerged and expanded in Monocotyledons (Tuominen et al., 2011; Peng et al., 2016). As a result, three additional ACT-like were found in barley and seven in rice. These enzymes use diverse amine acceptors. OsAHT1 and OsPHT3 are specific for agmatine like $H v \mathrm{ACT}$, whereas $H v \mathrm{THT} 2, H v \mathrm{THT} 7$, and $H v \mathrm{THT} 8$ are specific for tryptamine and OsTHT1, OsTHT2, OsTBT1, and OsTBT2 acylate tryptamine, serotonin, and tyramine (Burhenne et al., 2003; Tanabe et al., 2016; Ube et al., 2019b; Peng et al., 2019). The ability of several ACT-like to use tyramine and serotonin as substrates underlines a convergent evolution for tyramine and serotonin derived phenolamide synthesis in both Monocotyledons and Solanaceae using BAHD or GNAT acyltransferases, respectively (Peng et al., 2016). However, both enzymes, usually called THTs, should not be confused. Finally, an additional diversification in ACT-like acceptors was observed in rice for OsPHT and OsPHT3, which acylates a single amino group of putrescine (Tanabe et al., 2016). ACT-like isoforms are differentially expressed. Some are constitutively expressed in roots, flowers, or seedlings, whereas others are inducible upon pathogen challenge given defensive or developmental roles, depending on the phenolamide produced (Burhenne et al., 2003; Tanabe et al., 2016; Peng et al., 2019; Ube et al., 2019b).

As previously described, ACT-like were initially thought to be restricted to Monocotyledons until the OsPHT ortholog NaAT1 was identified in N. attenuata (Onkokesung et al., 2012). This explained the common reports of hydroxycinnamoyl putrescine accumulation in both Gramineae and Solanaceae under pathogen infection (Samborski and Rohringer, 1970; Klapheck, 1983; Torrigiani et al., 1997; Ogura et al., 2001; Pushpa et al., 2014; Burt et al., 2019), but also narrow conservation of the cluster HvACT in Eudicotyledons as argued by the distribution of putative orthologs among plants, as shown in Figure 5. However, compared to other BAHD clades, the absence of O-acyltransferases, in addition to $\mathrm{N}$ hydroxycinnamoyltransferases, in clade IV leads to the application of a non-selective threshold in sequences retained in our identification of putative HvACT orthologues. Consequently, most obtained accessions might be false positives, and conclusions on a wide distribution of $H v A C T$ clusters outside Monocotyledons are speculative. Since putrescine based phenolamides were reported outside Solanaceae, among Eudicotyledons (Martintanguy et al., 1978; Negrel, 1989; Kyselka et al., 2018; Elejalde-Palmett et al., 2015), their synthesis could also involve HvACT orthologues or any other Nhydroxycinnamoyltransferase clusters, such as $\mathrm{NaDH} 29$, AtSDT, Os12g27220, or one that is still unidentified. 


\subsection{Cluster AtACT1}

As mentioned above, agmatine-based phenolamides are widespread in monocotyledons. They involve members of the cluster HvACT for their synthesis. These compounds are also sporadically reported in Eudicotyledon species, including Arabidopsis or Albizzia (Ueda et al., 1997; Muroi et al., 2009). The acyltransferase AtACT1, involved in agmatine acylation in Arabidopsis, was isolated and belongs to clade Ia of BAHD. AtACT1 is highly divergent from cluster $H v A C T$ and corresponds to a second cluster of agmatine-specific Nhydroxycinnamoyltransferase, which seems to be restricted to Brassicales (Fig. 5) (Muroi et al., 2009).

\subsection{Clusters DcHCBT and AsHHT1}

Avenanthramides are specific to a small number of plant species and have only been reported in carnation and oat. The N-hydroxycinnamoyltransferases catalyzing acylation of anthranilate in these species were identified as hydroxycinnamoyl/benzoyl-CoA:anthranilate N-hydroxycinnamoyl/benzoyltransferase (DcHCBT) and HydroxycinnamoylCoA:Hydroxyanthranilate $N$ - Hydroxycinnamoyl Transferases (AsHHTs), respectively. They both belong to the BAHD clade Vb (Fig. 4) (Yang et al., 1997, 2004). However, DcHCBT and AsHHTs are not closely related and form two very small clusters that probably appeared recently and independently (Fig. 4 and Fig. 5). Additional gene duplication occurred in oat, leading to six putative HHT isoforms, including the characterized AsHHT1 and AsHHT4 (Li et al., 2019). The expression of DcHCBT and AsHHTs are mainly induced after pathogen infection in accordance with the phytoalexin function of avenanthramides (Yang et al., 1997, 2004).

\subsection{Clusters $N a \mathrm{DH} 29$, AtSDT and $O s 12 \mathrm{~g} 27220$}

Three distinct N-hydroxycinnamoyltransferase clusters, among the BAHD superfamily, decorate primary amino groups of linear polyamines (Fig. 4). The clusters AtSDT and Os $12 \mathrm{~g} 27220$ belong to the BAHD clade $\mathrm{Va}$ and catalyze the acylation of spermidine on primary amino groups at both extremities, leading to di-hydroxycinnamoyl spermidine, whereas the cluster $\mathrm{NaDH} 29$ belongs to clade IIIa and is only able to acylate a single primary amino group of spermidine or spermine, depending on the enzymes, leading to hydroxycinnamoyl spermidine $(\mathrm{NaDH} 29$ and $\mathrm{NaCV} 86)$ or hydroxycinnamoyl spermine (SmSpmHT and SrSpmHT). The three clusters may result from convergent evolution in distinct higher plants (Fig. 5); cluster Os12g27220 is restricted to Poales (Dong et al., 2015), cluster $\mathrm{NaDH} 29$ is restricted to Solanales (Onkokesung et al., 2012; Peng et al., 2019), and cluster AtSDT seems more widely distributed among Rosids (Luo et al., 2009). Therefore, mono- and di-hydroxycinnamoyl spermidines/spermines are reported in a lot of plants but seems to originate from multi-convergent evolution, highlighting the importance of these compounds in plants, although their functions are poorly understood. Expression profiles of enzymes between and within the three groups are not conserved but widely detected in various tissues, including seedlings, roots, leaves, flowers, fruits, and under herbivory attacks (Luo et al., 2009; Onkokesung et al., 2012; Dong et al., 2015; Peng et al., 2019). 


\subsection{Cluster AtSHT}

A fourth cluster of N-hydroxycinnamoyltransferases uses polyamines, mainly spermidine, as an acyl acceptor (Fig. 4). Cluster AtSHT belongs to BAHD clade Vb. The remarkable feature of the members of this cluster, so called SHT, compared to other $\mathrm{N}$ hydroxycinnamoyltransferases is their ability to catalyze acylation on secondary amino groups in addition to primary amino groups (Grienenberger et al., 2009). This particularity probably involves modification by an enzyme with linear polyamine conformation to allow access to the secondary amino group. Therefore, SHTs acylate every amino group of spermidine, leading to tri-hydroxycinnamoyl spermidine. Consequently, SHTs should not be confused with enzymes using spermidine as a substrate. Since the first characterization of AtSHT in Arabidopsis (Grienenberger et al., 2009), additional SHT-like enzymes have been successfully isolated in apple tree (MdSHT), chicory (CiSHT1 and CiSHT2), and eggplant (SmSHT1 and SrSHT1) (Elejalde-Palmett et al., 2015; Peng et al., 2016; Delporte et al., 2018). Further genomic studies have highlighted the important conservation of SHT as a single copy throughout core Eudicotyledons, and the absence of tri-hydroxycinnamoyl spermidine was only demonstrated in few Eudicotyledon orders, such as Gentianales, Malvales, Cucurbitales, or Fabales (Elejalde-Palmett et al., 2015). Therefore, the SHT cluster seems to be the most ubiquitous and widespread N-hydroxycinnamoyltransferase (Fig. 5). SHT probably appeared in ancestral core Eudicotyledons from gene duplication and neofunctionalization of HCT, a member of BAHD clade $\mathrm{Vb}$ involved in lignification of vascular plants (Besseau et al., 2007; Kriegshauser et al., 2020). In addition to spermidine, some SHTs use, to a lesser extent, putrescine as an acceptor, and a shift from spermidine to spermine was demonstrated in the Asteraceae leading to the synthesis of tetra-hydroxycinnamoyl spermine (Delporte et al., 2018). Interestingly, in the Asteraceae family, two copies of SHTs were identified, but this apparent functional redundancy was not addressed (Delporte et al., 2018). Finally, a second conserved trait of SHTs is their exclusive and restricted expression in tapetum cells of anthers (Grienenberger et al., 2009; Elejalde-Palmett et al., 2015), allowing accumulation of tri/tetra-hydroxycinnamoyl spermidine/spermine derivatives in the pollen cell wall of most core Eudicotyledons.

\subsection{Toward a third type of N-hydroxycinnamoyltransferase derived from polyketide synthases?}

Polyketide synthase (PKS) is a large family of multifunctional enzymes, restricted to bacteria, fungi, and plants. They catalyze sequential condensation of malonyl-CoA units on a starting CoA ester substrate such as acetyl-CoA, followed by polyketide scaffold rearrangement leading to natural products with high diversity and complex chemical structures (Shen 2003; Nivina et al., 2019). In plants, the chalcone synthase (CHS) is a particular PKS which uses hydroxycinnamoyl-CoA as a starting substrate and initiates flavonoid metabolic pathway. CHS-like PKSs catalyze Claisen condensation on a hydroxycinnamic moiety using three malonyl-CoA units, followed by a cyclisation (Austin et al., 2003; Dibyendu, 2015). Recently, the expression in yeast of a tomato genes cluster related to flavonoids reveals the ability of SlCHS to catalyze a $\mathrm{C}-\mathrm{N}$ bond formation between $p$-coumaroyl-CoA and hydroxyanthranilate, in addition to the canonical Claisen condensation ( $\mathrm{C}-\mathrm{C}$ bond) for 
flavonoid synthesis (Kong et al. 2020). The synthesis of $p$-coumaroyl hydroxyanthranilate by SlCHS, also reported for the Arabidopsis CHS, was 40-fold less efficient than its classical activity which may impair an active avenanthramide biosynthesis in tomato and Arabidopsis. However, this discovery rises the possibility of a punctual neofunctionalization of CHS-like PKSs leading to phenolamide emergence in some plant species. A screen for new activities of CHS and the related stilbene synthase (STS) with monoamines and aliphatic polyamines as substrates must be investigated in the future.

\subsection{Cytochromes P450 and O-methyltransferases as additional drivers of phenolamide diversification}

Apperarance of phenolamides in plants is directly linked to the emergence of new $\mathrm{N}$ hydroxycinnamoyltransferases with novel catalytic properties. As already mentioned, Nhydroxycinnamoyltransferases are usually more selective on acyl acceptor than on acyl donor. Consequently, the hydroxylation and the methylation of the hydroxycinnamoyl groups may occur before their transfer to the amines. However, chemical diversification among biosynthetic pathways derived from phenylpropanoids is generally dictated by cytochromes P450 and O-methyltransferases (Vogt, 2010) and the phenolamide pathway does not appeared as an exception. In wheat, CYP98A11 and CYP98A12 were reported for the first time to effectively hydroxylate $p$-coumaroyl tyramine in vitro (Morant et al., 2007). More recently, high substrate plasticity has been demonstrated for some members of the CYP98A family among terrestrial plants, some of them being able to hydroxylate in vitro the hydroxycinnamic moiety of phenolamides (Alber et al., 2019). The CYP98A family is widely distributed among terrestrial plants and mainly dedicated to catalyze the hydroxylation of the p-coumaroyl shikimate ester for the biosynthesis of monolignols (Alber and Ehlting, 2012). However, in angiosperms, a second copy of CYP98A has also been reported with a wide range of substrates among phenolic compounds (Alber et al., 2019). This additional copy may be recruited to catalyze the decoration of new phenolic compounds such as phenolamides. Such a neofunctionalization has been demonstrated in planta for the CYP98A8 and CYP98A9 paralogs involved in the synthesis of tri-hydroxycinnamoyl spermidine in Arabidopsis stamens (Matsuno et al., 2009; Liu et al., 2016). CYP98A8 and CYP98A9 are Brassicaceae-specific duplicates of the ancestral CYP98A3 involved in the synthesis of monolignols in vascular tissues (Liu et al., 2016). Evolutionary driven change in tissue expression associated with substrate plasticity may have contributed to this metabolic diversification (Matsuno et al., 2009). CYP98A8 and CYP98A9 retain regiospecificity for 3'hydroxylation, but CYP98A8 also evolved to acquire additional 5'-hydroxylation activity (Matsuno et al., 2009; Liu et al., 2016). Unlike the exclusive expression of CYP98A8 in tapetum cells, CYP98A9 is also expressed in many tissues, and corresponds to an unfixed functional copy of CYP98A involved in the metabolism of flavonoids (Matsuno et al., 2009; Liu et al., 2016). In addition to CYP98A8 and CYP98A9, the synthesis of trihydroxycinnamoyl spermidine in Arabidopsis involve the caffeoyl CoA 3-Omethyltransferase 1 (AtCCoAOMT1) and the tapetum-specific methyltransferase 1 (AtTSM1), two divergent O-methyltransferases of the CCoAOMT family (Fellenberg et al., 2008, 2009, 2012). AtCCoAOMT1 catalyzes the 3'-OH methylation of caffeoyl-CoA to 
feruloyl-CoA in vascular tissue, as a critical step in phenylpropanoid metabolism for the synthesis of monolignol. AtCCoAOMT1 probably retained the same activity / substrates in tapetum cells for methylation of hydroxycinnamoyl fractions prior to their transfer to spermidine (Fellenberg et al., 2009, 2012). In contrast, the expression of AtTSM1 is strictly coordinated with SHT and CYP98A8 in the tapetum, and catalyzes the 5'-OH methylation of tri-5-OH-feruloyl spermidine, thus acting after the transfer of hydroxycinnamoyl groups to the spermidine (Fellenberg et al., 2008). Although both OMTs are required for the synthesis of tri-hydroxycinnamoyl spermidine, only TSM1 has evolved to directly use phenolamide as substrates. Remarkably, the co-emergence of TSM1 and CYP98A8 in the Brassicaceae is responsible for the accumulation of spermidine coupled to the sinapoyl group, which has not been reported to date in other Eudicotyledons. Indeed, SHTs are not able to use this bulky acyl donor as a substrate (Grienenberger et al., 2009). Finally, the metabolic intermediates leading to the tri-hydroxycinnamoyl spermidines biosynthesis is not well established. Whereas the 5'-methoxylation occurs unequivocally on hydroxycinnamoyl groups coupled to spermidine, the contradictory results on substrate forms used by CYP98A9 and CCoAOMT (amide and CoA ester respectively) keep open the involvement of 3'-methoxylation on hydroxycinnamoyl moieties before or after transfer to spermidine. Both hypotheses are possible since SHT efficiently uses $p$-coumaroyl-CoA and feruloyl-CoA as acyl donors. This example showing the gain of function of P450s and OMTs for the diversification of trihydroxycinnamoyl spermidine from duplicated ancestral genes implies that similar process may have occurred on other phenolamide biosynthetic branches. This may deserve our attention in the future.

\subsection{Phenolamide glycosylation and transport}

Glycosylated phenolamides have been detected in the seeds of rye, barley, corn, foxtail millet and maize (Luo et al., 2009; Pihlava, 2014; Pihlava et al., 2018; Li et al., 2018; Xiang et al., 2019), in tobacco leaves ( $\mathrm{Li}$ et al., 2018) and in Arabidopsis and chicory flowers (Fellenberg

et al., 2009; Handrick et al., 2010; Delporte et al., 2018). The enzymes catalyzing their glycosylation remain unknown. However, the glycosylated forms being often detected as minor compounds compared to the free phenolamides, it may involve unspecialised and large-substrate accepting UDP-glycosyltransferases.

As previously presented in this review, the incorporation of phenolamides into the cell wall (Clarke and McCaig, 1982; Negrel et al., 1996; McLusky et al., 1999; King and Calhoun, 2005; Ishihara et al., 2008) and their localization on the surface of the pollen grain (Grienenberger et al., 2009, Delporte et al., 2018) imply their transport in the apoplast. Several membrane transporters involved in the release of parietal precursors from tapetum for the formation of sporopollenin have been characterized as the ABC transporters ABCG26 / ABCG3 for the polyketide (Quilichini et al., 2014; lefèvre et al., 2018) or the NPF transporter FST1 for the flavonol glycosides (Grunewald et al., 2020), but the tri-hydroxycinnamoyl spermidine transporters have not been identified. Multi-drug and toxic compound extrusion transporters (MATEs) are the best candidates for the transport of phenolamide across the membrane, as recently exemplified by the leaf export of $p$-coumaroylagmatine through 
DTX18 in Arabidopsis (Dobritzsch et al., 2016), but alternatively, the involvement of secretory vesicle systems could not be excluded (Xu et al., 2014).

\section{Conclusion and remaining challenges}

As highlighted in this review, knowledge about phenolamides has increased considerably over the last decade, particularly with respect to their structural diversity and the mechanisms underlying their biosynthesis. Connecting these two aspects, it appears obvious that challenges remain in understanding and discovering all enzymes enabling the biosynthesis of this great chemical diversity. Presently, no enzyme catalyzing the di-acylation of putrescine, agmatine, or cadaverine has been reported. In addition, the coupling of dihydrocaffeoyl moieties to spermine, which leads to the promising therapeutic kukoamines, is still not resolved at the enzymatic level. This raises the question of the emergence of other $\mathrm{N}$ hydroxycinnamoyltransferase clusters or diversification of already described ones. Behind these evolutionary aspects, structure-function analyses are urgently needed to identify key amino acids controlling enzyme specificity. Yet, no representative crystal structure of the above-mentioned $\mathrm{N}$-hydroxycinnamoyltransferase clusters is available and the only few attempts of in silico modeling and docking simulations were not experimentally confirmed by mutant analysis (Peng et al., 2016; 2019). Likewise, subcellular organization of these pathways has still to be elucidated. Albeit subcellular localization has been demonstrated for some enzymes (Delporte et al., 2018), micro-compartmentation of these pathways must not be excluded. Many proteins involved in the phenylpropanoid pathway are assembled in supramolecular complex called metabolons (Ralston and Yu, 2006; Laursen et al., 2015). Particularly, considering that multiple acylation steps can occur, it is tempting to suggest an organization in metabolons of certain of these enzymes with other actors of the phenylpropanoid pathway. Indeed, it is not clear whether the intermediates are kept within the active site of the enzymes to complete acylations or if the intermediates are channeled between enzymes. This will deserve further investigations. Moreover, since a large amount of phenolamide dimers are now being described, knowledge regarding their dimerization is still to be uncovered. In barley, peroxidases have been suggested to catalyze the dimerization of hydroxycinnamoylagmatine to hordatine (Negrel and Smith, 1984; Burhenne et al., 2003). However, neither the enzyme nor the gene has been characterized to date (Nomura et al., 2007). The implication of other enzyme families needs to be investigated. As mentioned above, the role of cytochromes P450, O-methyl-transferases and polyketide synthases in the phenolamide pathway may have heretofore been underestimated. All these questions highlight the need to include more plant models in phenolamide metabolism studies. One of them should be plants from the genus Lycium. In this solanaceous genus, more than 42 phenolamide structures have been reported, including kukoamines, dimers, and glycosylated forms (Qian et al., 2017), but nothing has been described at the enzymatic level, which offers 
a fantastic playground for discovering new enzymes. Those compounds may have a role in plants, in terms of their defense. Therefore, the optimization of their biosynthesis in plant organs is one of the ways to favor the biological control of pests and diseases. Functional roles of phenolamides, in terms of therapeutic and human health beneficial aspects, need further investigation. Two reviews have been published this year on these questions (Wang et al., 2020; Roumani et al., 2020). Research efforts focused on the added value of consuming food products rich in phenolamides (oat, barley, eggplant, tomato, and pepper, among others) appear essential. 


\section{Acknowledgments}

We thank the Ministry of Interior and Municipalities; Habbouche City Council, Lebanon for the 3 year PhD grant attributed to MR during her period at the Agronomy and Environment laboratory (LAE).

\section{Author Contributions}

MR, CR, RL, SB, and DG designed the study. All authors contributed to write the introduction and conclusion. DG wrote the section "reproductive role". MR, CR, and RL wrote sections related to biotic and abiotic stress, and the regulatory aspects. SB wrote the section related to origins and evolution of phenolamide metabolism. The whole manuscript and different sections were revised and corrected by all authors. They read and approved the final version of the manuscript.

\section{Funding}

The $\mathrm{PhD}$ grant of MR was attributed by the Ministry of the Interior and Municipalities, Habbouche City Council, Lebanon. The other authors were funded by INRAe (RL and CR), Université de Lille (DG), and Université de Tours (SB). 


\section{References:}

Abe K, Matsuura H, Ukai M, Shimura H, Koshino H, Suzuki T. 2017. N-1, N-14diferuloylspermine as an antioxidative phytochemical contained in leaves of Cardamine fauriei. Bioscience Biotechnology and Biochemistry 81, 1855-1860.

Alamgir KM, Hojo Y, Christeller JT, Fukumoto K, Isshiki R, Shinya T, Baldwin IT, Galis I. 2016. Systematic analysis of rice (Oryza sativa) metabolic responses to herbivory. Plant, Cell \& Environment 39, 453-466.

Alber A.V., and Ehlting J. 2012. Chapter 4 - Cytochrome P450s in Lignin Biosynthesis. In Advances in Botanical Research, L. Jouanin, and C. Lapierre, eds. (Academic Press), pp. 113143.

Alber A.V., Renault H., Basilio- Lopes A., Bassard J.-E., Liu Z., Ullmann P., Lesot A., Bihel F., Schmitt M., Werck- Reichhart D., Ehlting J. 2019. Evolution of coumaroyl conjugate 3hydroxylases in land plants: lignin biosynthesis and defense. The Plant Journal. 99, 924-936.

Ariizumi T, Toriyama K. 2011. Genetic regulation of sporopollenin synthesis and pollen exine development. Annual Review of Plant Biology 62, 437-460.

Austin, M.B. and Noel, J.P. 2003. The chalcone synthase superfamily of type III polyketide synthases. Natural Product Reports 20, 79-110.

Baker CJ, Whitaker BD, Roberts DP, Mock NM, Rice CP, Deahl KL, Aver'yanov AA. 2005. Induction of redox sensitive extracellular phenolics during plant-bacterial interactions. Physiological and Molecular Plant Pathology 66, 90-98.

Bassard J-E, Ullmann P, Bernier F, Werck-Reichhart D. 2010. Phenolamides: Bridging polyamines to the phenolic metabolism. Phytochemistry 71, 1808-1824.

Besseau S, Hoffmann L, Geoffroy P, Lapierre C, Pollet B, Legrand M. 2007. Flavonoid accumulation in Arabidopsis repressed in lignin synthesis affects auxin transport and plant growth. The Plant Cell 19, 148-162.

Bouchereau A, Aziz A, Larher F, Martin-Tanguy J. 1999. Polyamines and environmental challenges: recent development. Plant Science 140, 103-125.

Bozorov TA, Pandey SP, Dinh ST, Kim S-G, Heinrich M, Gase K, Baldwin IT. 2012. DICERlike proteins and their role in plant-herbivore interactions in Nicotiana attenuata. Journal of Integrative Plant Biology 54, 189-206.

Burhenne K, Kristensen BK, Rasmussen SK. 2003. A new class of Nhydroxycinnamoyltransferases purification, cloning, and expression of a barley agmatine coumaroyltransferase (EC 2.3.1.64). Journal of Biological Chemistry 278, 13919-13927.

Burt AJ, Arnason JT, García-Lara S. 2019. Natural variation of hydroxycinnamic acid amides in maize landraces. Journal of Cereal Science 88, 145-149. 
Cabanne F, Dalebroux MA, Martin- Tanguy J, Martin C. 1981. Hydroxycinnamic acid amides and ripening to flower of Nicotiana tabacum var. xanthi n.c. Physiologia Plantarum 53, 399-404.

Campos L, Lisón P, López-Gresa MP, Rodrigo I, Zacarés L, Conejero V, Bellés JM. 2014. Transgenic tomato plants overexpressing tyramine N-Hydroxycinnamoyltransferase exhibit elevated hydroxycinnamic acid amide levels and enhanced resistance to Pseudomonas syringae. Molecular Plant-Microbe Interactions 27, 1159-1169.

Chen H, Jones AD, Howe GA. 2006. Constitutive activation of the jasmonate signaling pathway enhances the production of secondary metabolites in tomato. FEBS Letters 580, 2540-2546.

Choi SW, Lee SK, Kim EO, Oh JH, Yoon KS, Parris N, Hicks KB, Moreau RA. 2007. Antioxidant and antimelanogenic activities of polyamine conjugates from corn bran and related hydroxycinnamic acids. Journal of Agricultural and Food Chemistry 55, 3920-3925.

Clarke J.M., McCaig T.N. 1982. Excised-leafwater retention capabilities as an indicator of drought resistance of Triticum genotypes. Canadian Journal of Plant Science 62, 571-578.

D'Auria JC. 2006. Acyltransferases in plants: a good time to be BAHD. Current Opinion in Plant Biology 9, 331-340.

Delporte M, Bernard G, Legrand G, Hielscher B, Lanoue A, Molinié R, Rambaud C, Mathiron D, Besseau S, Linka N, Hilbert J-L, Gagneul D. 2018. A BAHD neofunctionalization promotes tetrahydroxycinnamoyl spermine accumulation in the pollen coats of the Asteraceae family. Journal of Experimental Botany 69, 5355-5371.

Demkura PV, Abdala G, Baldwin IT, Ballare CL. 2010. Jasmonate-dependent and -independent pathways mediate specific effects of solar ultraviolet B radiation on leaf phenolics and antiherbivore defense. Plant Physiology 152, 1084-1095.

Dibyendu D.M. 2015. A brief review on plant type III polyketide synthase an important group of enzyme of secondar metabolism. Research Journal of Recent Sciences 4, 138-147.

Ding X, Wang X, Li Q, Yu L, Song Q, Gai J, Yang S. 2019. Metabolomics studies on cytoplasmic male sterility during flower bud development in soybean. International Journal of Molecular Sciences 20, 2869.

Dobritzsch M, Lübken T, Eschen-Lippold L, Gorzolka K, Blum E, Matern A, Marillonnet S, Böttcher C, Dräger B, Rosahl S. 2016. MATE transporter-dependent export of hydroxycinnamic acid amides. The Plant Cell 28, 583-596.

Dong X, Gao Y, Chen W, Wang W, Gong L, Liu X, Luo J. 2015. Spatiotemporal distribution of phenolamides and the genetics of natural variation of hydroxycinnamoyl spermidine in rice. Molecular Plant 8, 111-121.

Edreva A, Yordanov I, Kardjieva R, Hadjiiska E, Gesheva E. 1995. Expression of phenylamides in abiotic stress conditions. Bulg. J. Plant Physiol, 15-23. 
Edreva A, Yordanov I, Kardjieva R, Gesheva E. 1998. Heat shock responses of bean plants: involvement of free radicals, antioxidants and free radical/active oxygen scavenging systems. Biologia Plantarum 41, 185-191.

Edreva AM, Velikova VB, Tsonev TD. 2007. Phenylamides in plants. Russian Journal of Plant Physiology 54, 287-301.

Elejalde-Palmett C, Bernonville D, Dugé T, Glevarec G, Pichon O, Papon N, Courdavault V, StPierre B, Giglioli-Guivarc'h N, Lanoue A, Besseau S. 2015. Characterization of a spermidine hydroxycinnamoyltransferase in Malus domestica highlights the evolutionary conservation of trihydroxycinnamoyl spermidines in pollen coat of core Eudicotyledons. Journal of Experimental Botany 66, 7271-7285.

Facchini PJ, Hagel J, Zulak KG. 2002. Hydroxycinnamic acid amide metabolism: physiology and biochemistry. Canadian Journal of Botany 80, 577-589.

Farmer MJ, Czernic P, Michael A, Negrel J. 1999. Identification and characterization of cDNA clones encoding hydroxycinnamoyl-CoA:tyramine N-hydroxycinnamoyltransferase from tobacco. European Journal of Biochemistry 263, 686-694.

Fellenberg C., Milkowski C., Hause B., Lange P.-R., Böttcher C., Schmidt J., and Vogt T. 2008. Tapetum-specific location of a cation-dependent O-methyltransferase in Arabidopsis thaliana. The Plant Journal 56, 132-145.

Fellenberg C, Böttcher C, Vogt T. 2009. Phenylpropanoid polyamine conjugate biosynthesis in Arabidopsis thaliana flower buds. Phytochemistry 70, 1392-1400.

Fellenberg C, Handrick V, Ziegler J, Vogt T. 2012. Polyamine homeostasis in wild type and phenolamide deficient Arabidopsis thaliana stamens. Frontiers in Plant Science 3. 180.

Fellenberg C, Vogt T. 2015. Evolutionarily conserved phenylpropanoid pattern on angiosperm pollen. Trends in Plant Science 20, 212-218.

Gális I, Šimek P, Narisawa T, Sasaki M, Horiguchi T, Fukuda H, Matsuoka K. 2006. A novel R2R3 MYB transcription factor NtMYBJS1 is a methyl jasmonate-dependent regulator of phenylpropanoid-conjugate biosynthesis in tobacco. The Plant Journal 46, 573-592.

Gaquerel E, Kotkar H, Onkokesung N, Galis I, Baldwin IT. 2013. Silencing an N-acyltransferaselike involved in lignin biosynthesis in Nicotiana attenuata dramatically alters herbivory-induced phenolamide metabolism. PLOS ONE 8, e62336.

Gaquerel E, Gulati J, Baldwin IT. 2014. Revealing insect herbivory-induced phenolamide metabolism: from single genes to metabolic network plasticity analysis. The Plant Journal 79, 679-692.

Georgiev L, Chochkova M, Ivanova G, Najdenski H, Ninova M, Milkova T. 2012. Radical scavenging and antimicrobial activities of cinnamoyl amides of biogenic monoamines. Rivista Italiana Delle Sostanze Grasse 89, 91. 
Grienenberger E, Besseau S, Geoffroy P, Debayle D, Heintz D, Lapierre C, Pollet B, Heitz T, Legrand M. 2009. A BAHD acyltransferase is expressed in the tapetum of Arabidopsis anthers and is involved in the synthesis of hydroxycinnamoyl spermidines. The Plant Journal 58, 246259.

Guo D-P, Sun Y-Z, Chen Z-J. 2003. Involvement of polyamines in cytoplasmic male sterility of stem mustard (Brassica juncea var. tsatsai). Plant Growth Regulation 41, 33-40.

Grunewald S., Marillonnet S., Hause G., Haferkamp I., Neuhaus H.E., Veß A., Hollemann T., Vogt, T. 2020. The tapetal major facilitator NPF2.8 is required for accumulation of flavonol glycosides on the pollen surface in Arabidopsis thaliana. Plant Cell 32, 1727-1748.

Halitschke R, Baldwin IT. 2003. Antisense LOX expression increases herbivore performance by decreasing defense responses and inhibiting growth-related transcriptional reorganization in Nicotiana attenuata. The Plant Journal 36, 794-807.

Handrick V., Vogt T., Frolov, A. 2010. Profiling of hydroxycinnamic acid amides in Arabidopsis thaliana pollen by tandem mass spectrometry. Analytical and Bioanalytical Chemistry 398, 2789-2801.

Hess MW. 1993. Cell-wall development in freeze-fixed pollen: Intine formation of Ledebouria socialis (Hyacinthaceae). Planta 189, 139-149.

Hohlfeld H, Schurmann W, Scheel D, Strack D. 1995. Partial purification and characterization of hydroxycinnamoyl-Coenzyme A:tyramine hydroxycinnamoyltransferase from cell suspension cultures of Solanum tuberosum. Plant Physiology 107, 545-552.

Ishihara A., Hashimoto Y., Tanaka C., Dubouzet J.G., Nakao T., Matsuda F., Nishioka T., Miyagawa H., Wakasa K. 2008. The tryptophan pathway is involved in the defense responses of rice against pathogenic infection via serotonin production. The Plant Journal 54, 481-495.

Kage U, Yogendra KN, Kushalappa AC. 2017. TaWRKY70 transcription factor in wheat QTL2DL regulates downstream metabolite biosynthetic genes to resist Fusarium graminearum infection spread within spike. Scientific Reports 7, 1-14.

Kang K, Park S, Kim YS, Lee S, Back K. 2009. Biosynthesis and biotechnological production of serotonin derivatives. Applied Microbiology and Biotechnology 83, 27-34.

Kaur H, Heinzel N, Schoettner M, Baldwin IT, Galis I. 2010. R2R3-NaMYB8 regulates the accumulation of phenylpropanoid-polyamine conjugates, which are essential for local and systemic defense against insect herbivores in Nicotiana attenuata. Plant Physiology 152, 17311747.

King RR, Calhoun LA. 2005. Characterization of cross-linked hydroxycinnamic acid amides isolated from potato common scab lesions. Phytochemistry 66, 2468-2473.

Klapheck S. 1983. Polyamines and cinnamoyl-putrescines in normal and sulfur-starved suspension cultures of Nicotiana tabacum. Zeitschrift für Pflanzenphysiologie 112, 275-279. 
Kong D., Li S., Smolke C.D. 2020. Discovery of a previously unknown biosynthetic capacity of naringenin chalcone synthase by heterologous expression of a tomato gene cluster in yeast. Science Advances. 6, eabd1143.

Königshofer H, Lechner S. 2002. Are polyamines involved in the synthesis of heat-shock proteins in cell suspension cultures of tobacco and alfafa in response to high-temperature stress? Plant Physiology and Biochemistry 40, 51-59.

Kriegshauser L, Knosp S, Grienenberger E, Gütle D, Sørensen I, Herrgott L, Zumsteg J, Rose J, Reski R, Werck-Reichhart D, Renault H 2020. Function of the hydroxycinnamoyl-coA:shikimate hydroxycinnamoyl transferase is evolutionarily conserved in embryophytes. bioRxiv300285.

Kyselka J, Bleha R, Dragoun M, Bialasová K, Horáčková Š, Schätz M, Sluková M, Filip V, Synytsya A. 2018. Antifungal polyamides of hydroxycinnamic acids from sunflower bee pollen. Journal of Agricultural and Food Chemistry 66, 11018-11026.

Langebartels C, Kerner K, Leonardi S, Schraudner M, Trost M, Heller W, Sandermann H. 1991. Biochemical-plant responses to ozone: Differential induction of polyamine and ethylene biosynthesis in tobacco. Plant Physiology 95, 882-889.

Larbat R, Paris C, Le Bot J, Adamowicz S. 2014. Phenolic characterization and variability in leaves, stems and roots of Micro-Tom and patio tomatoes, in response to nitrogen limitation. Plant Science 224, 62-73.

Laursen T., Møller B.L., and Bassard J.-E. 2015. Plasticity of specialized metabolism as mediated by dynamic metabolons. Trends in Plant Science 20, 20-32

Lefèvre F., Fourmeau J., Pottier M., Baijot A., Cornet T., Abadía J., Álvarez-Fernández A., Boutry, M. 2018. The Nicotiana tabacum ABC transporter NtPDR3 secretes O-methylated coumarins in response to iron deficiency. Journal of Experimental Botany 69, 4419-4431.

Li, J., Zhang, K., Meng, Y., Hu, J., Ding, M., Bian, J., et al. 2018. Jasmonic acid/ethylene signaling coordinates hydroxycinnamic acid amides biosynthesis through ORA59 transcription factor. The Plant Journal 95, 444-457.

Li Z, Zhao C, Zhao X, Xia Y, Sun X, Xie W, Ye Y, Lu X, Xu G. 2018. Deep annotation of hydroxycinnamic acid amides in plants based on ultra-high-performance liquid chromatographyhigh-resolution mass spectrometry and its in silico database. Analytical Chemistry 90, 1432114330 .

Li Z, Chen Y, Meesapyodsuk D, Qiu X. 2019. The biosynthetic pathway of major avenanthramides in oat. Metabolites. 8,163.

Liu Z., Tavares R., Forsythe E.S., André F., Lugan R., Jonasson G., Boutet-Mercey S., Tohge T., Beilstein M.A., Werck-Reichhart D., Renault H. 2016. Evolutionary interplay between sister cytochrome P450 genes shapes plasticity in plant metabolism. Nature Communications 7, 13026. 
López-Gresa MP, Maltese F, Bellés JM, Conejero V, Kim HK, Choi YH, Verpoorte R. 2010. Metabolic response of tomato leaves upon different plant-pathogen interactions. Phytochemical Analysis 21, 89-94.

Lopez-Gresa MP, Lison P, Yenush L, Conejero V, Rodrigo I, Belles JM. 2016. Salicylic acid is involved in the basal resistance of tomato plants to Citrus exocortis viroid and tomato spotted wilt virus. Plos One 11, e0166938.

Lou Y-R, Bor M, Yan J, Preuss AS, Jander G. 2016. Arabidopsis NATA1 acetylates putrescine and decreases defense-related hydrogen peroxide accumulation. Plant Physiology 171 14431455 .

Luo J, Fuell C, Parr A, Hill L, Bailey P, Elliott K, Fairhurst SA, Martin C, Michael AJ. 2009. A novel polyamine acyltransferase responsible for the accumulation of spermidine conjugates in arabidopsis seed. Plant Cell 21, 318-333.

Macoy DM, Kim W-Y, Lee SY, Kim MG. 2015. Biotic stress related functions of hydroxycinnamic acid amide in plants. Journal of Plant Biology 58, 156-163.

McLusky S.R., Bennett M.H., Beale M.H., Lewis M.J., Gaskin P., Mansfield J.W. 1999. Cell wall alterations and localized accumulation of feruloyl-3'-methoxytyramine in onion epidermis at sites of attempted penetration by Botrytis allii are associated with actin polarisation, peroxidase activity and suppression of flavonoid biosynthesis. The Plant Journal. 17, 523-534.

Marti G, Erb M, Boccard J, Glauser G, Doyen GR, Villard N, Robert CAM, Turlings TCJ, Rudaz S, Wolfender J-L. 2013. Metabolomics reveals herbivore-induced metabolites of resistance and susceptibility in maize leaves and roots. Plant, Cell \& Environment 36, 621-639.

Martin-Tanguy J, Cabanne F, Perdrizet E, Martin C. 1978. The distribution of hydroxycinnamic acid amides in flowering plants. Phytochemistry 17, 1927-1928.

Martin-Tanguy J. 1985. The occurrence and possible function of hydroxycinnamoyl acid amides in plants. Plant Growth Regulation 3, 381-399.

Martin-Tanguy J. 1997. Conjugated polyamines and reproductive development: Biochemical, molecular and physiological approaches. Physiol, Piant, 675-688.

Matsuda F, Morino K, Ano R, Kuzawa M, Wakasa K, Miyagawa H. 2005. Metabolic flux analysis of the phenylpropanoid pathway in elicitor-treated potato tuber tissue. Plant and Cell Physiology 46, 454-466.

Matsuno M, Compagnon V, Schoch GA, Schmitt M, Debayle D, Bassard J-E, Pollet B, Hehn A, Heintz D, Ullmann P, Lapierre C, Bernier F, Ehlting J, Werck-Reichhart D. 2009. Evolution of a novel phenolic pathway for pollen development. Science 325, 1688-1692.

Meurer B, Wiermann R, Strack D. 1988. Phenylpropanoid pattern in Fagales pollen and their phylogenetic relevance. Phytochemistry 27, 803-828. 
Mikkelsen BL, Olsen CE, Lyngkjær MF. 2015. Accumulation of secondary metabolites in healthy and diseased barley, grown under future climate levels of $\mathrm{CO}_{2}$, ozone and temperature. Phytochemistry 118, 162-173.

Morant M., Schoch G.A., Ullmann P., Ertunç T., Little D., Olsen C.E., Petersen M., Negrel J., Werck-Reichhart D. 2007. Catalytic activity, duplication and evolution of the CYP98 cytochrome P450 family in wheat. Plant Molecular Biology 1, 1-19.

Morimoto N, Ueno K, Teraishi M, Okumoto Y, Mori N, Ishihara A. 2018. Induced phenylamide accumulation in response to pathogen infection and hormone treatment in rice (Oryza sativa). Bioscience, Biotechnology, and Biochemistry 82, 407-416.

Muroi A, Ishihara A, Tanaka C, Ishizuka A, Takabayashi J, Miyoshi H, Nishioka T. 2009. Accumulation of hydroxycinnamic acid amides induced by pathogen infection and identification of agmatine coumaroyltransferase in Arabidopsis thaliana. Planta 230, 517-527.

Muroi A, Matsui K, Shimoda T, Kihara H, Ozawa R, Ishihara A, Nishihara M, Arimura G. 2012. Acquired immunity of transgenic torenia plants overexpressing agmatine coumaroyltransferase to pathogens and herbivore pests. Scientific Reports 2, 689.

Negrel J, Martin C. 1984. The biosynthesis of feruloyltyramine in Nicotiana tabacum. Phytochemistry 23, 2797-2801.

Negrel J, Jeandet P. 1987. Metabolism of tyramine and feruloyltyramine in TMV inoculated leaves of Nicotiana tabacum. Phytochemistry 26, 2185-2190.

Negrel J. 1989. The biosynthesis of cinnamoylputrescines in callus tissue cultures of Nicotiana tabacum. Phytochemistry 28, 477-481.

Negrel J, Pollet B, Lapierre C. 1996. Ether-linked ferulic acid amides in natural and wound periderms of potato tuber. Phytochemistry 43, 1195-1199.

Negrel J, Javelle F. 1997. Purification, characterization and partial amino acid sequencing of hydroxycinnamoyl-CoA: tyramine $\mathrm{N}$-(hydroxycinnamoyl)transferase from tobacco cellsuspension cultures. European Journal of Biochemistry 247, 1127-1135.

Newman MA, von Roepenack-Lahaye E, Parr A, Daniels MJ, Dow JM. 2001. Induction of hydroxycinnamoyl-tyramine conjugates in pepper by Xanthomonas campestris, a plant defense response activated by $h r p$ gene-dependent and hrp gene-independent mechanisms. Molecular plant-microbe interactions $14,785-792$.

Nivina A., Yuet K.P., Hsu J., Khosla C. 2019. Evolution and Diversity of Assembly-Line Polyketide Synthases. Chemical Reviews. 119, 12524-12547.

Novo M, Silvar C, Merino F, Martinez-Cortes T, Lu F, Ralph J, Pomar F. 2017. Deciphering the role of the phenylpropanoid metabolism in the tolerance of Capsicum annuum L. to Verticillium dahliae Kleb. Plant Science 258, 12-20. 
Ogura Y, Ishihara A, Iwamura H. 2001. Induction of hydroxycinnamic acid amides and tryptophan by jasmonic acid, abscisic acid and osmotic stress in barley leaves. Zeitschrift für Naturforschung C 56, 193-202.

Onkokesung N, Gaquerel E, Kotkar H, Kaur H, Baldwin IT, Galis I. 2012. MYB8 controls inducible phenolamide levels by activating three novel hydroxycinnamoyl-Coenzyme A:polyamine transferases in Nicotiana attenuata. Plant Physiology 158, 389-407.

Pandey SP, Baldwin IT. 2007. RNA-directed RNA polymerase 1 (RdR1) mediates the resistance of Nicotiana attenuata to herbivore attack in nature. The Plant Journal 50, 40-53.

Paschold A, Halitschke R, Baldwin IT. 2007. Co(i)-ordinating defenses: NaCOI1 mediates herbivore- induced resistance in Nicotiana attenuata and reveals the role of herbivore movement in avoiding defenses. The Plant Journal 51, 79-91.

Pearce G, Marchand PA, Griswold J, Lewis NG, Ryan CA. 1998. Accumulation of feruloyltyramine and $p$-coumaroyltyramine in tomato leaves in response to wounding. Phytochemistry 47, 659-664.

Pegg AE.2008. Spermidine/spermine-N(1)-acetyltransferase: a key metabolic regulator. Am J Physiol Endocrinol Metab 294(6), 995-1010.

Peng H, Yang T, Whitaker BD, Trouth F, Shangguan L, Dong W, Jurick WM. 2016. Characterization of spermidine hydroxycinnamoyl transferases from eggplant (Solanum melongena L.) and its wild relative Solanum richardii Dunal. Horticulture Research 3, 16062.

Peng, H., Meyer, R. S., Yang, T., Whitaker, B. D., Trouth, F., Shangguan, L., Huang J., Litt, A., Little, D.P, Ke, H., Jurick W.M. 2019. A novel hydroxycinnamoyl transferase for synthesis of hydroxycinnamoyl spermine conjugates in plants. BMC Plant Biol. 19, 261.

Pihlava J.-M. 2014. Identification of hordatines and other phenolamides in barley (Hordeum vulgare) and beer by UPLC-QTOF-MS. Journal of Cereal Science 60, 645-652.

Pihlava J.-M., Hellström J., Kurtelius T., Mattila, P. 2018. Flavonoids, anthocyanins, phenolamides, benzoxazinoids, lignans and alkylresorcinols in rye (Secale cereale) and some rye products. Journal of Cereal Science 79, 183-192.

Pradhan M, Pandey P, Gase K, Sharaff M, Singh RK, Sethi A, Baldwin IT, Pandey SP. 2017. Argonaute 8 (AGO8) Mediates the elicitation of direct defenses against herbivory. Plant Physiology 175, 927-946.

Pushpa D, Yogendra KN, Gunnaiah R, Kushalappa AC, Murphy A. 2014. Identification of late blight resistance-related metabolites and genes in potato through nontargeted metabolomics. Plant Molecular Biology Reporter 32, 584-595.

Qian D., Zhao Y., Yang G., Huang L. 2017. Systematic Review of Chemical Constituents in the Genus Lycium (Solanaceae). Molecules 22, 911. 
Quilichini T.D., Samuels A.L., Douglas C.J. 2014. ABCG26-mediated polyketide trafficking and hydroxycinnamoyl spermidines contribute to pollen wall exine formation in arabidopsis. Plant Cell 26, 4483-4498.

Quilichini TD, Grienenberger E, Douglas CJ. 2015. The biosynthesis, composition and assembly of the outer pollen wall: A tough case to crack. Phytochemistry 113, 170-182.

Ralston L., and Yu O. 2006. Metabolons involving plant cytochrome P450s. Phytochemistry Reviews 5, 459-472.

Rayapuram C, Baldwin IT. 2007. Increased SA in NPR1-silenced plants antagonizes JA and JAdependent direct and indirect defenses in herbivore-attacked Nicotiana attenuata in nature. The Plant Journal52, 700-715.

Roepenack-Lahaye E von, Newman M-A, Schornack S, Hammond-Kosack KE, Lahaye T, Jones JDG, Daniels MJ, Dow JM. 2003. p-Coumaroylnoradrenaline, a novel plant metabolite implicated in tomato defense against pathogens. Journal of Biological Chemistry 278, 43373-3383.

Roumani M., Duval R.E., Ropars A., Risler A., Robin C., Larbat R. 2020. Phenolamides: Plant specialized metabolites with a wide range of promising pharmacological and health-promoting interests. Biomedicine and Pharmacotherapy. 131, 110762.

Royer M, Larbat R, Le Bot J, Adamowicz S, Nicot PC, Robin C. 2016. Tomato response traits to pathogenic Pseudomonas species: Does nitrogen limitation matter? Plant Science 244, 57-67.

Ryabinine AA, Ilina EM. 1949. Dokl. Akad. Nauk SSSR, 513.

Salah Ud-Din AIM, Tikhomirova A, Roujeinikova A. 2016. Structure and functional diversity of GCN5-Related N-acetyltransferases (GNAT). International Journal of Molecular Sciences 17, 1018.

Samborski DJ, Rohringer R. 1970. Abnormal metabolites of wheat: Occurrence, isolation and biogenesis of 2-hydroxyputrescine amides. Phytochemistry 9, 1939-1945.

Schäfer M, Meza- Canales ID, Brütting C, Baldwin IT, Meldau S. 2015. Cytokinin concentrations and Chase-Domain Containing His Kinase 2 (NaCHK2)- and NaCHK3-mediated perception modulate herbivory-induced defense signaling and defenses in Nicotiana attenuata. New Phytologist 207, 645-658.

Schmidt A, Scheel D, Strack D. 1998. Elicitor-stimulated biosynthesis of hydroxycinnamoyltyramines in cell suspension cultures of Solanum tuberosum. Planta 205, 5155.

Shevyakova NI, Rakitin VYu, Stetsenko LA, Aronova EE, Kuznetsov VV. 2006. Oxidative stress and fluctuations of free and conjugated polyamines in the halophyte Mesembryanthemum crystallinum L. under $\mathrm{NaCl}$ salinity. Plant Growth Regulation 50, 69-78. 
Shen B. 2003. Polyketide biosynthesis beyond the type I, II and III polyketide synthase paradigms. Current Opinion in Chemical Biology 7, 285-295.

Shi Z, Wei F, Wan R, Li Y, Wang Y, An W, Qin K, Dai G, Cao Y, Feng J. 2019. Impact of nitrogen fertilizer levels on metabolite profiling of the Lycium barbarum L. fruit. Molecules 24, 3879.

Stitz M, Baldwin IT, Gaquerel E. 2011. Diverting the flux of the JA pathway in Nicotiana attenuata compromises the plant's defense metabolism and fitness in nature and glasshouse. Plos One 6, e25925.

Stoessl A, Unwin CH. 1970. The antifungal factors in barley. V. Antifungal activity of the hordatines. Canadian Journal of Botany 48, 465-470.

Tanabe K, Hojo Y, Shinya T, Galis I. 2016. Molecular evidence for biochemical diversification of phenolamide biosynthesis in rice plants. Journal of Integrative Plant Biology 58, 903-913.

Tebayashi S, Horibata Y, Mikagi E, Kashiwagi, T, Mekuria DB, Dekebo A, Ishihara A, Kim C-S. 2007. Induction of resistance against the leafminer, Liriomyza trifolii, by jasmonic acid in sweet pepper. Bioscience, Biotechnology, and Biochemistry 71, 1521-1526.

Tiburcio AF, Kaur-Sawhneyz R, Galston AW. 1993. Spermidine biosynthesis as affected by osmotic stress in oat leaves. Plant Growth Regulation 13, 103-109.

Torrigiani P, Rabiti AL, Bortolotti C, Betti L, Marani F, Canova A, Bagni N. 1997. Polyamine synthesis and accumulation in the hypersensitive response to TMV in Nicotiana tabacum. New Phytologist 135, 467-473.

Tuominen LK, Johnson VE, Tsai C-J. 2011. Differential phylogenetic expansions in BAHD acyltransferases across five angiosperm taxa and evidence of divergent expression among Populus paralogues. BMC Genomics 12, 236.

Ube N, Nishizaka M, Ichiyanagi T, Ueno K, Taketa S, Ishihara A. 2017. Evolutionary changes in defensive specialized metabolism in the genus Hordeum. Phytochemistry 141, 1-10.

Ube N, Harada D, Katsuyama Y, Osaki-Oka K, Tonooka T, Ueno K, Taketa S, Ishihara A. 2019a. Identification of phenylamide phytoalexins and characterization of inducible phenylamide metabolism in wheat. Phytochemistry 167, 112098.

Ube N, Yabuta Y, Tohnooka T, Ueno K, Taketa S, Ishihara A. 2019b. Biosynthesis of phenylamide phytoalexins in pathogen-infected barley. International Journal of Molecular Sciences 20, 5541.

Ueda M, Tashiro C, Yamamura S. 1997. cis-p-coumaroylagmatine, the genuine leaf-opening substance of a nyctinastic plant, Albizzia julibrissin Durazz. Tetrahedron Letters 38, 3253-3256. 
Vetting MW, S de Carvalho LP, Yu M, Hegde SS, Magnet S, Roderick SL, Blanchard JS. 2005. Structure and functions of the GNAT superfamily of acetyltransferases. Arch Biochem Biophys 433(1), 212-26.

Vogt T. 2010. Phenylpropanoid biosynthesis. Molecular Plant 3, 2-20.

Vogt T. 2018. Unusual spermine-conjugated hydroxycinnamic acids on pollen: function and evolutionary advantage. Journal of Experimental Botany 69, 5311-5315.

Wang W., Snooks H.D. Sang S. 2020. The Chemistry and Health Benefits of Dietary Phenolamides. Journal of Agricultural and Food Chemistry 68, 6248-6267.

Xiang J., Zhang M., Apea-Bah F.B., Beta T. 2019. Hydroxycinnamic acid amide (HCAA) derivatives, flavonoid C-glycosides, phenolic acids and antioxidant properties of foxtail millet. Food Chemistry 295, 214-223.

Xin Z, Yu Z, Erb M, Turlings TCJ, Wang B, Qi J, Liu S, Lou Y. 2012. The broad-leaf herbicide 2,4-dichlorophenoxyacetic acid turns rice into a living trap for a major insect pest and a parasitic wasp. The New Phytologist 194, 498-510.

Xu J., Ding Z., Vizcay-Barrena G., Shi J., Liang W., Yuan Z., Werck-Reichhart D., Schreiber L., Wilson Z.A., Zhang, D. 2014. Aborted Microspores acts as a master regulator of pollen wall formation in arabidopsis. Plant Cell 26, 1544-1556.

Yang Q, Reinhard K, Schiltz E, Matern U. 1997. Characterization and heterologous expression of hydroxycinnamoyl/benzoyl-CoA:anthranilate N-hydroxycinnamoyl/benzoyltransferase from elicited cell cultures of carnation, Dianthus caryophyllus L. Plant Molecular Biology 35, 777789.

Yang Q, Trinh HX, Imai S, Ishihara A, Zhang L, Nakayashiki H, Tosa Y, Mayama S. 2004. Analysis of the involvement of hydroxyanthranilate hydroxycinnamoyltransferase and caffeoylCoA 3-O-methyltransferase in phytoalexin biosynthesis in oat. Molecular plant-microbe interactions. Molecular Plant-Microbe Interactions. 17, 81-89.

Yogendra KN, Kumar A, Sarkar K, Li Y, Pushpa D, Mosa KA, Duggavathi R, Kushalappa AC. 2015. Transcription factor StWRKY1 regulates phenylpropanoid metabolites conferring late blight resistance in potato. Journal of Experimental Botany 66, 7377-7389.

Yogendra KN, Kushalappa AC. 2016. Integrated transcriptomics and metabolomics reveal induction of hierarchies of resistance genes in potato against late blight. Functional Plant Biology $43,766-782$.

Yogendra KN, Sarkar K, Kage U, Kushalappa AC. 2017. Potato NAC43 and MYB8 Mediated transcriptional regulation of secondary cell wall biosynthesis to contain Phytophthora infestans infection. Plant Molecular Biology Reporter 35, 519-533. 
Zacarés L, López-Gresa MP, Fayos J, Primo J, Bellés JM, Conejero V. 2007. Induction of $p$ coumaroyldopamine and feruloyldopamine, two novel metabolites, in tomato by the bacterial pathogen Pseudomonas syringae. Molecular Plant-Microbe Interactions 20, 1439-1448.

Zhang H, Liu R, Lu Q. 2020. Separation and Characterization of phenolamines and flavonoids from rape bee pollen, and comparison of their antioxidant activities and protective effects against oxidative stress. Molecules 25, 1264.

Zhu YQ, Zhu DY, Yin L, Zhang Y, Vonrhein C, Wang DC. 2006. Crystal structure of human spermidine/spermineN1-acetyltransferase (hSSAT): The first structure of a new sequence family of transferase homologous superfamily. Proteins 63, 1127-1131. 
Table 1: Characterized N-hyroxycinnamoyltransferases involved in phenolamide biosynthesis.

\begin{tabular}{|c|c|c|c|c|c|c|c|c|c|c|c|}
\hline \multirow[t]{2}{*}{$\begin{array}{l}\text { Cluster } \\
\text { name }\end{array}$} & \multirow[t]{2}{*}{$\begin{array}{l}\text { Superfa } \\
\text { milly }\end{array}$} & \multirow{2}{*}{$\begin{array}{l}\text { Fami } \\
\text { lly or } \\
\text { Clad } \\
\text { e }\end{array}$} & \multirow[t]{2}{*}{$\begin{array}{l}\text { Enzyme } \\
\text { name }\end{array}$} & \multirow[t]{2}{*}{ Species } & \multirow[t]{2}{*}{$\begin{array}{l}\text { Expression } \\
\text { profile }\end{array}$} & \multicolumn{2}{|l|}{ Substrats } & \multicolumn{2}{|c|}{$\begin{array}{l}\text { Catalytic } \\
\text { properties }\end{array}$} & \multirow[t]{2}{*}{$\begin{array}{l}\text { Accession } \\
\text { number }\end{array}$} & \multirow[t]{2}{*}{ References } \\
\hline & & & & & & Acceptors & $\begin{array}{l}\text { CoA- } \\
\text { ester } \\
\text { donors }\end{array}$ & $\begin{array}{l}\text { Type } \\
\text { of } \\
\text { amino } \\
\text { group } \\
\text { acylat } \\
\text { ed }\end{array}$ & $\begin{array}{l}\text { Number } \\
\text { of } \\
\text { substitu } \\
\text { tion } \\
\text { catalyse } \\
\text { d }\end{array}$ & & \\
\hline \multirow{4}{*}{ StTHT } & GNAT & DAT & StTHT & $\begin{array}{l}\text { Solanum } \\
\text { tuberosum }\end{array}$ & $\begin{array}{l}\text { Induced by } \\
\text { virus and } \\
\text { phytopatho } \\
\text { gens, root }\end{array}$ & $\begin{array}{l}\text { Tyramine, } \\
\text { octopamin } \\
\text { e }\end{array}$ & $\mathrm{Ci}, \mathrm{Fe}$ & $1^{\circ}$ & Mono & AB061243 & Schmidt 1999 \\
\hline & GNAT & DAT & $\begin{array}{l}\text { NtTHT10 } \\
/ 30\end{array}$ & $\begin{array}{l}\text { Nicotiana } \\
\text { tabacum }\end{array}$ & $\begin{array}{l}\text { Induced by } \\
\text { phytopatho } \\
\text { gens }\end{array}$ & $\begin{array}{l}\text { Tyramine, } \\
\text { octopamin } \\
\text { e }\end{array}$ & $\mathrm{Fe}$ & $1^{\circ}$ & Mono & AJ005062 & Farmer et al. 1999 \\
\hline & GNAT & DAT & $\begin{array}{l}\text { NtTHT4/ } \\
11\end{array}$ & $\begin{array}{l}\text { Nicotiana } \\
\text { tabacum }\end{array}$ & $\begin{array}{l}\text { Induced by } \\
\text { phytopatho } \\
\text { gens }\end{array}$ & $\begin{array}{l}\text { Tyramine, } \\
\text { octopamin } \\
\text { e }\end{array}$ & $\mathrm{Fe}$ & $1^{\circ}$ & Mono & AJ131767 & Farmer et al. 1999 \\
\hline & GNAT & DAT & SITHT1-3 & $\begin{array}{l}\text { Solanum } \\
\text { lycopersicum }\end{array}$ & $\begin{array}{l}\text { Leaf, } \\
\text { induced by } \\
\text { phytopatho } \\
\text { gens }\end{array}$ & $\begin{array}{l}\text { Tyramine, } \\
\text { noradrena } \\
\text { line, } \\
\text { dopamine, } \\
\text { octopamin } \\
\text { e }\end{array}$ & $\mathrm{pC}$ & $1^{\circ}$ & Mono & AY081905 & $\begin{array}{l}\text { Von roepenack- } \\
\text { lahaye et al. } 2003\end{array}$ \\
\hline
\end{tabular}




\begin{tabular}{|c|c|c|c|c|c|c|c|c|c|c|c|}
\hline & GNAT & DAT & SITHT7-1 & $\begin{array}{l}\text { Solanum } \\
\text { lycopersicum }\end{array}$ & Leaf & $\begin{array}{l}\text { Tyramine, } \\
\text { noradrena } \\
\text { line, } \\
\text { dopamine, } \\
\text { octopamin } \\
\text { e }\end{array}$ & $\mathrm{pC}$ & $1^{\circ}$ & Mono & AY081906 & $\begin{array}{l}\text { Von roepenack- } \\
\text { lahaye et al. } 2003\end{array}$ \\
\hline & GNAT & DAT & SITHT7-8 & $\begin{array}{l}\text { Solanum } \\
\text { lycopersicum }\end{array}$ & Leaf & $\begin{array}{l}\text { Tyramine, } \\
\text { noradrena } \\
\text { line, } \\
\text { dopamine, } \\
\text { octopamin } \\
\text { e }\end{array}$ & $\mathrm{pC}$ & $1^{\circ}$ & Mono & AY081907 & $\begin{array}{l}\text { Von roepenack- } \\
\text { lahaye et al. } 2003\end{array}$ \\
\hline & GNAT & DAT & CaTHT & $\begin{array}{l}\text { Capsicum } \\
\text { annuum }\end{array}$ & Stem, root & Tyramine & $\mathrm{Fe}, \mathrm{pC}$ & $1^{\circ}$ & Mono & AY819700 & Kang et al. 2006 \\
\hline & GNAT & DAT & CaSHT & $\begin{array}{l}\text { Capsicum } \\
\text { annuum }\end{array}$ & $\begin{array}{l}\text { Flower, } \\
\text { stem, UV- } \\
\text { induced }\end{array}$ & $\begin{array}{l}\text { Serotonin, } \\
\text { tyramine }\end{array}$ & $\begin{array}{l}\text { Caf, Fe, } \\
\mathrm{pC}\end{array}$ & $1^{\circ}$ & Mono & AF329463 & $\begin{array}{l}\text { Back et al. 2001, Kang } \\
\text { et al. } 2006\end{array}$ \\
\hline \multirow{7}{*}{ HvACT } & BAHD & IV & HvACT & $\begin{array}{l}\text { Hordeum } \\
\text { vulgare }\end{array}$ & $\begin{array}{l}\text { Seedling, } \\
\text { induced by } \\
\text { phytopatho } \\
\text { gens }\end{array}$ & Agmatine & $\begin{array}{l}\mathrm{Ci}, \mathrm{pC}, \mathrm{Fe}, \\
\text { Caf }\end{array}$ & $1^{\circ}$ & Mono & AY228552 & Burhenne et al. 2003 \\
\hline & BAHD & IV & HvTHT7 & $\begin{array}{l}\text { Hordeum } \\
\text { vulgare }\end{array}$ & $\begin{array}{l}\text { Induced by } \\
\text { phytopatho } \\
\text { gens }\end{array}$ & $\begin{array}{l}\text { Tryptamin } \\
\text { e, } \\
\text { serotonin }\end{array}$ & $\mathrm{Ci}, \mathrm{Fe}, \mathrm{pC}$ & $1^{\circ}$ & Mono & $\begin{array}{l}\text { Hr1G0194 } \\
10.1\end{array}$ & Ube et al. 2019 \\
\hline & BAHD & IV & HvTHT8 & $\begin{array}{l}\text { Hordeum } \\
\text { vulgare }\end{array}$ & $\begin{array}{l}\text { Induced by } \\
\text { phytopatho } \\
\text { gens }\end{array}$ & $\begin{array}{l}\text { Tryptamin } \\
\text { e, } \\
\text { serotonin }\end{array}$ & $\mathrm{Ci}, \mathrm{Fe}, \mathrm{pC}$ & $1^{\circ}$ & Mono & $\begin{array}{l}\text { Hr1G0777 } \\
80.1\end{array}$ & Ube et al. 2019 \\
\hline & BAHD & IV & HvTHT2 & $\begin{array}{l}\text { Hordeum } \\
\text { vulgare }\end{array}$ & $\begin{array}{l}\text { Induced by } \\
\text { phytopatho } \\
\text { gens }\end{array}$ & $\begin{array}{l}\text { Tryptamin } \\
\text { e, } \\
\text { serotonin, } \\
\text { tyramine }\end{array}$ & $\mathrm{Fe}$ & $1^{\circ}$ & Mono & $\begin{array}{l}\text { Hr1G0777 } \\
90.1\end{array}$ & Ube et al. 2019 \\
\hline & BAHD & IV & OsAHT1 & Oryza sativa & Root, flower & Agmatine & $\mathrm{Fe}$ & $1^{\circ}$ & Mono & BAS91492 & Tanabe et al. 2016 \\
\hline & BAHD & IV & OsPHT3 & Oryza sativa & Root, flower & $\begin{array}{l}\text { Agmatine, } \\
\text { putrescine }\end{array}$ & $\mathrm{pC}, \mathrm{Fe}$ & $1^{\circ}$ & Mono & BAT09225 & Tanabe et al. 2016 \\
\hline & BAHD & IV & OsPHT & Oryza sativa & $\begin{array}{l}\text { Root, } \\
\text { flower, } \\
\text { wounding }\end{array}$ & Putrescine & $\mathrm{Fe}, \mathrm{pC}$ & $1^{\circ}$ & Mono & ВАT09226 & Tanabe et al. 2016 \\
\hline
\end{tabular}




\begin{tabular}{|c|c|c|c|c|c|c|c|c|c|c|c|}
\hline & BAHD & IV & OsTHT1 & Oryza sativa & nd & $\begin{array}{l}\text { Tryptamin } \\
\text { e, } \\
\text { serotonin, } \\
\text { tyramine }\end{array}$ & $\begin{array}{l}\text { pC, Caf, } \\
\mathrm{Bz}\end{array}$ & $1^{\circ}$ & Mono & $\begin{array}{l}\text { Os10g233 } \\
10\end{array}$ & Peng et al. 2016a \\
\hline & BAHD & IV & OsTHT2 & Oryza sativa & nd & $\begin{array}{l}\text { Tryptamin } \\
\text { e, } \\
\text { serotonin, } \\
\text { tyramine }\end{array}$ & $\begin{array}{l}\mathrm{pC}, \text { Caf, } \\
\mathrm{Fe}\end{array}$ & $1^{\circ}$ & Mono & $\begin{array}{l}\text { Os10g238 } \\
20\end{array}$ & Peng et al. 2016a \\
\hline & BAHD & IV & OsTBT1 & Oryza sativa & nd & $\begin{array}{l}\text { Tryptamin } \\
\text { e, } \\
\text { serotonin, } \\
\text { tyramine }\end{array}$ & $\begin{array}{l}\mathrm{pC}, \mathrm{Bz} \\
\text { Caf }\end{array}$ & $1^{\circ}$ & Mono & $\begin{array}{l}\text { Os11g422 } \\
90\end{array}$ & Peng et al. 2016a \\
\hline & BAHD & IV & OsTBT2 & Oryza sativa & nd & $\begin{array}{l}\text { Tryptamin } \\
\text { e, } \\
\text { serotonin, } \\
\text { tyramine }\end{array}$ & $\mathrm{Bz}$ & $1^{\circ}$ & Mono & $\begin{array}{l}\text { Os11g423 } \\
70\end{array}$ & Peng et al. 2016a \\
\hline & BAHD & IV & NaAT1 & $\begin{array}{l}\text { Nicotiana } \\
\text { attenuata }\end{array}$ & $\begin{array}{l}\text { Induced by } \\
\text { herbivore } \\
\text { attack }\end{array}$ & Putrescine & Caf, Fe & $1^{\circ}$ & Mono & JN390826 & $\begin{array}{l}\text { Onkokesung et al. } \\
2012\end{array}$ \\
\hline AtACT1 & BAHD & la & AtACT1 & $\begin{array}{l}\text { Arabidopsis } \\
\text { thaliana }\end{array}$ & $\begin{array}{l}\text { Induced by } \\
\text { phytopatho } \\
\text { gens }\end{array}$ & Agmatine & $\mathrm{pC}, \mathrm{Fe}$ & $1^{\circ}$ & Mono & ВT011800 & Muroi et al. 2009 \\
\hline \multirow{4}{*}{$\mathrm{NaDH} 29$} & BAHD & Illa & NaCV86 & $\begin{array}{l}\text { Nicotiana } \\
\text { attenuata }\end{array}$ & $\begin{array}{l}\text { Induced by } \\
\text { herbivore } \\
\text { attack }\end{array}$ & $\begin{array}{l}\text { Acylated } \\
\text { spermidin } \\
\text { e }\end{array}$ & pC, Caf & $1^{\circ}$ & Mono & JN390825 & $\begin{array}{l}\text { Onkokesung et al. } \\
2012\end{array}$ \\
\hline & BAHD & IIIa & $\mathrm{NaDH} 29$ & $\begin{array}{l}\text { Nicotiana } \\
\text { attenuata }\end{array}$ & $\begin{array}{l}\text { Induced by } \\
\text { herbivore } \\
\text { attack }\end{array}$ & $\begin{array}{l}\text { Spermidin } \\
\mathrm{e}\end{array}$ & $\begin{array}{l}\text { Caf, Fe, } \\
\mathrm{pC}\end{array}$ & $1^{\circ}$ & Mono & JN390824 & $\begin{array}{l}\text { Onkokesung et al. } \\
2012\end{array}$ \\
\hline & BAHD & Illa & $\begin{array}{l}\text { SmSpmH } \\
\mathrm{T}\end{array}$ & $\begin{array}{l}\text { Solanum } \\
\text { melangena }\end{array}$ & nd & Spermine & $\mathrm{pC}$ & $1^{\circ}$ & Mono & KP233218 & Peng et al. 2019 \\
\hline & BAHD & Illa & SrSpmHT & $\begin{array}{l}\text { Solanum } \\
\text { richardii }\end{array}$ & Fruit & Spermine & $\begin{array}{l}\text { pC, Fe, } \\
\text { Caf }\end{array}$ & $1^{\circ}$ & Mono & KR150683 & Peng et al. 2019 \\
\hline \multirow[t]{2}{*}{ AtSDT } & BAHD & Va & AtSCT & $\begin{array}{l}\text { Arabidopsis } \\
\text { thaliana }\end{array}$ & Root & $\begin{array}{l}\text { Spermidin } \\
\mathrm{e}\end{array}$ & $\mathrm{pC}$ & $1^{\circ}$ & $\mathrm{Di}$ & $\begin{array}{l}\text { NM12807 } \\
2\end{array}$ & Luo et al. 2009 \\
\hline & BAHD & Va & AtSDT & $\begin{array}{l}\text { Arabidopsis } \\
\text { thaliana }\end{array}$ & $\begin{array}{l}\text { Silique, } \\
\text { seedling }\end{array}$ & $\begin{array}{l}\text { Spermidin } \\
\mathrm{e}\end{array}$ & S & $1^{\circ}$ & $\mathrm{Di}$ & $\begin{array}{l}\text { NM12791 } \\
5\end{array}$ & Luo et al. 2009 \\
\hline Os12g27 & BAHD & Va & Os12g27 & Oryza sativa & Leaf & Spermidin & $\mathrm{pC}, \mathrm{Fe}$ & $1^{\circ}$ & Di & ABA98379 & Dong et al. 2015 \\
\hline
\end{tabular}




\begin{tabular}{|c|c|c|c|c|c|c|c|c|c|c|c|}
\hline \multirow[t]{2}{*}{220} & \multicolumn{4}{|c|}{220} & \multirow[b]{2}{*}{$\begin{array}{l}\text { Various } \\
\text { tissues }\end{array}$} & \multicolumn{2}{|l|}{$\mathrm{e}$} & \multirow[b]{2}{*}{$1^{\circ}$} & \multirow[b]{2}{*}{ Di } & \multirow[b]{2}{*}{ ABG22016 } & \multirow[b]{2}{*}{ Dong et al. 2015} \\
\hline & BAHD & $\mathrm{Va}$ & $\begin{array}{l}\text { Os12g27 } \\
254\end{array}$ & Oryza sativa & & $\begin{array}{l}\text { Spermidin } \\
\mathrm{e}\end{array}$ & $\mathrm{pC}, \mathrm{Fe}$ & & & & \\
\hline \multirow{11}{*}{ AtSHT } & BAHD & $\mathrm{Vb}$ & AtSHT & $\begin{array}{l}\text { Arabidopsis } \\
\text { thaliana }\end{array}$ & Tapetum & $\begin{array}{l}\text { Spermidin } \\
\mathrm{e}\end{array}$ & $\begin{array}{l}\text { Fe, Caf, } \\
\mathrm{pC}, \mathrm{Ci}\end{array}$ & $\begin{array}{l}1^{\circ} \text { and } \\
2^{\circ}\end{array}$ & Tri & $\begin{array}{l}\text { NM12746 } \\
4\end{array}$ & $\begin{array}{l}\text { Grienenberger et al. } \\
2009\end{array}$ \\
\hline & BAHD & $\mathrm{Vb}$ & MdSHT & $\begin{array}{l}\text { Malus } \\
\text { domestica }\end{array}$ & Anther & $\begin{array}{l}\text { Spermidin } \\
\mathrm{e}\end{array}$ & $\begin{array}{l}\mathrm{pC}, \mathrm{Fe}, \\
\text { Caf }\end{array}$ & $\begin{array}{l}1^{\circ} \text { and } \\
2^{\circ}\end{array}$ & Tri & ALF00095 & $\begin{array}{l}\text { Elejalde-palmett et } \\
\text { al. } 2015\end{array}$ \\
\hline & BAHD & $\mathrm{Vb}$ & $\mathrm{NtSHT}$ & $\begin{array}{l}\text { Nicotiana } \\
\text { tabacum }\end{array}$ & nd & $\begin{array}{l}\text { Spermidin } \\
\mathrm{e}\end{array}$ & $\begin{array}{l}\mathrm{pC}, \mathrm{Fe}, \\
\text { Caf }\end{array}$ & $\begin{array}{l}1^{\circ} \text { and } \\
2^{\circ}\end{array}$ & Tri & $\begin{array}{l}\text { MN78704 } \\
5\end{array}$ & $\begin{array}{l}\text { Personal } \\
\text { communication }\end{array}$ \\
\hline & BAHD & $\mathrm{Vb}$ & SISHT & $\begin{array}{l}\text { Solanum } \\
\text { lycopersicum }\end{array}$ & nd & $\begin{array}{l}\text { Spermidin } \\
\text { e }\end{array}$ & $\begin{array}{l}\text { Fe, pC, } \\
\text { Caf }\end{array}$ & $\begin{array}{l}1^{\circ} \text { and } \\
2^{\circ}\end{array}$ & Tri & $\begin{array}{l}\text { MN78704 } \\
4\end{array}$ & $\begin{array}{l}\text { Personal } \\
\text { communication }\end{array}$ \\
\hline & BAHD & $\mathrm{Vb}$ & RicSHT & Ricinus comunis & nd & $\begin{array}{l}\text { Spermidin } \\
\mathrm{e}\end{array}$ & Fe, Caf & $\begin{array}{l}1^{\circ} \text { and } \\
2^{\circ}\end{array}$ & Tri & $\begin{array}{l}\text { MN78704 } \\
3\end{array}$ & $\begin{array}{l}\text { Personal } \\
\text { communication }\end{array}$ \\
\hline & BAHD & $\mathrm{Vb}$ & VvSHT & Vitis vinifera & nd & $\begin{array}{l}\text { Spermidin } \\
\mathrm{e}\end{array}$ & $\mathrm{Fe}, \mathrm{pC}$ & $\begin{array}{l}1^{\circ} \text { and } \\
2^{\circ}\end{array}$ & Tri & $\begin{array}{l}\text { MN78704 } \\
7\end{array}$ & $\begin{array}{l}\text { Personal } \\
\text { communication }\end{array}$ \\
\hline & BAHD & $\mathrm{Vb}$ & RocSHT & Rosa canina & nd & $\begin{array}{l}\text { Spermidin } \\
\mathrm{e}\end{array}$ & $\mathrm{pC}, \mathrm{Fe}$ & $\begin{array}{l}1^{\circ} \text { and } \\
2^{\circ}\end{array}$ & Tri & $\begin{array}{l}\text { MN78704 } \\
6\end{array}$ & $\begin{array}{l}\text { Personal } \\
\text { communication }\end{array}$ \\
\hline & BAHD & $\mathrm{Vb}$ & SmSHT1 & $\begin{array}{l}\text { Solanum } \\
\text { melangena }\end{array}$ & $\begin{array}{l}\text { Flower, } \\
\text { fruit, } \\
\text { induced by } \\
\text { abiotic } \\
\text { stress }\end{array}$ & $\begin{array}{l}\text { Spermidin } \\
\text { e, } \\
\text { spermine }\end{array}$ & $\begin{array}{l}\text { Caf, Fe, } \\
\mathrm{pC}\end{array}$ & $\begin{array}{l}1^{\circ} \text { and } \\
2^{\circ}\end{array}$ & Tri & KP165410 & Peng et al. 2016b \\
\hline & BAHD & $\mathrm{Vb}$ & SrSHT1 & $\begin{array}{l}\text { Solanum } \\
\text { richardii }\end{array}$ & nd & $\begin{array}{l}\text { Spermidin } \\
\text { e, } \\
\text { spermine }\end{array}$ & $\begin{array}{l}\text { Caf, Fe, } \\
\mathrm{pC}\end{array}$ & $\begin{array}{l}1^{\circ} \text { and } \\
2^{\circ}\end{array}$ & Tri & KP165411 & Peng et al. 2016b \\
\hline & BAHD & $\mathrm{Vb}$ & CiSHT1 & $\begin{array}{l}\text { Cichorium } \\
\text { intybus }\end{array}$ & Flower & $\begin{array}{l}\text { Spermine, } \\
\text { spermidin } \\
\text { e }\end{array}$ & $\begin{array}{l}\text { pC, Caf, } \\
\mathrm{Fe}, \mathrm{Ci}\end{array}$ & $\begin{array}{l}1^{\circ} \text { and } \\
2^{\circ}\end{array}$ & Tetra & $\begin{array}{l}\text { MG45724 } \\
3\end{array}$ & Delporte et al. 2018 \\
\hline & BAHD & $\mathrm{Vb}$ & CiSHT2 & $\begin{array}{l}\text { Cichorium } \\
\text { intybus }\end{array}$ & Flower & $\begin{array}{l}\text { Spermine, } \\
\text { spermidin } \\
\mathrm{e}\end{array}$ & $\begin{array}{l}\mathrm{pC}, \mathrm{Caf} \\
\mathrm{Fe}, \mathrm{Ci}\end{array}$ & $\begin{array}{l}1^{\circ} \text { and } \\
2^{\circ}\end{array}$ & Tetra & $\begin{array}{l}\text { MG45724 } \\
4\end{array}$ & Delporte et al. 2018 \\
\hline DcHCBT & BAHD & $\mathrm{Vb}$ & DcHCBT & $\begin{array}{l}\text { Dianthus } \\
\text { caryophyllus }\end{array}$ & $\begin{array}{l}\text { Induced by } \\
\text { phytopatho } \\
\text { gens }\end{array}$ & $\begin{array}{l}\text { Anthranila } \\
\text { te }\end{array}$ & $\mathrm{Ci}, \mathrm{pC}, \mathrm{Bz}$ & $1^{\circ}$ & Mono & Z84383 & Yang et al. 1997 \\
\hline AsHHT1 & BAHD & $\mathrm{Vb}$ & AsHHT1 & Avena sativa & $\begin{array}{l}\text { Induced by } \\
\text { phytopatho } \\
\text { gens }\end{array}$ & $\begin{array}{l}5 \mathrm{OH}- \\
\text { anthranila } \\
\text { te }\end{array}$ & pC, Caf & $1^{\circ}$ & Mono & AB076980 & $\begin{array}{l}\text { Yang et al. 2004; Li et } \\
\text { al. } 2019\end{array}$ \\
\hline
\end{tabular}


$5 \mathrm{OH}-$

anthranila

pC, Caf

$1^{\circ}$

te

Acceptor and donor substrates are listed in range of efficienty. Ci, cinnamoyl; pC, p-coumaroyl; Caf, cafferoyl; Fe, feruloyl; S, sinapoyl; Bz, benzoyl; nd, not determined. Enzymes are first regroup depending on phenolamide synthetised, sub-groups represent common evolutive origin. 
Figure legends:

Figure 1 Schematic representation of the connections between the phenylpropanoid and mono- poly-amine pathways at the origin of phenolamide structural diversity. The six main phenolic acids constituting acyl donors are represented as CoA esters. The major groups of amines used as acyl acceptors are described together with their amino acid precursors. The final enzymatic step leading to phenolamide biosynthesis is supported by Nhydroxycinnamoyltransferases harboring specificity toward amine moieties. Few structures representative of phenolamide diversity are indicated, additional structures are given in Supplemental Figure 1.

Figure 2 Timeline showing the evolution of studies on phenolamides: Three main periods can be distinguished. The first one from 1949, when the first phenolamide was identified until the review of Edreva et al. in 2007. The second period was from 2007 to 2015, and the last period from 2015 to the present. The blue boxes represent the major breakthroughs of each period. In the white boxes, major reviews are indicated.

Figure 3 Phylogeny of characterized N-hydroxycinnamoyltransferases. Protein sequences were aligned using ClustalX, and the phylogenic tree was constructed using neighbor joining and bootstrap analysis. Black names correspond to the DAT family of GNAT acyltransferases for which only two representative members characterized in mammals and plants are mentioned (HsSAT1 and AtNATA1). Colored names represent BAHD acyltransferases clades for which every characterized member is mentioned: clade Ia (blue), clade II (yellow), clade IIIa (magenta), clade IIIb (cyan), clade IV (orange), clade $\mathrm{Va}$ (red), and clade Vb (green). Nhydroxycinnamoyltransferases are indicated in bold, and clusters are highlighted with dark lines or marked with an asterisk. Amine acceptors used by members of each $\mathrm{N}$ hydroxycinnamoyltransferase clusters are mentioned.

Figure 4 Mechanisms of phenolamide accumulation under biotic stress in plants. The orange box represents the mechanisms described in response to pathogen infection and the green box those in response to herbivory. Transcription factors are in bold and phytohormones in blue. In the case of pathogen infection, phenolamide accumulation relies on ethylene (ET) and jasmonic acid (JA) signaling pathways. ET activates different transcription factors (ERF, NAC) and ends by activating MYB factors that induce the expression of genes of the phenylpropanoid pathway, together with acyltransferases. In Arabidopsis, JA activates the AtORA59 factor, which leads immediately to overexpression of the AtACT enzyme. Finally, a third pathway implies the activation of WRKY transcription factors through the MAPK pathway. In the case of herbivory, the JA signaling pathway is mainly activated. Once JA is accumulated, Coronatine Intensitive1 (COI1) degrades the Jasmonate Zim-Domain (JAZ) proteins and releases transcription factors belonging to the bHLH family MYC. The release of MYC2 activates the MYB transcription factor. Herbivory also induces the accumulation of other phytohormones and SmRNA, which can modulate the JA dependent response and/or contribute to a systemic accumulation of phenolamides. The mechanisms for such aspects of the regulation are still unclear. Plain lines represent a direct relationship between these elements, whereas dotted lines represent relationships between elements with probable intermediates. PAL: Phenylalanine Ammonia Lyase; 4CL: 4-coumarate: CoA ligase; C4H: Cinnamate-4-Hydroxylase; CP: CaffeoylPutrescine; CoP: $p$-coumaroylPutrescine; FP: FeruloylPutrescine; MCS: MonoCaffeoylSpermidine; DCS: DiCaffeoylSpermidine; CoT : $p$-coumaroylTyramine ; FT : FeruloylTyramine ; CoN : $p$ - 
coumaroylNoradrenaline ; CoOc : p-coumaroylOctopamine ; CoD : p-coumaroylDopamine ; FD : FeruloylDopamine ; IAA : Indole Acetic Acid ; CK : Cytokinine ; SA : Salicylic Acid.

Figure 5 Distribution of putative N-hydroxycinnamoyltransferase orthologues among Tracheophyta species. Putative orthologues of N-hydroxycinnamoyltransferase were identified as described in Supplemental Figure 2. Hit numbers among plant orders for the accessions previously obtained were summarized in the table for each $\mathrm{N}$-hydroxycinnamoyltransferase clusters. To avoid confusion between orders without identified orthologues, due to limitations in data availability rather than lack of orthologues, we applied our method on AtHCT. Since it is assumed that HCT is needed for lignification in Tracheophyta and is maintained among land plants (Kriegshauser et al. 2020), we specifically mention plant orders with hits for HCT orthologues. Therefore, the absence of hits for an N-hydroxycinnamoyltransferase cluster within an order indicated in the table, corresponds to the absence of predicted orthologues. In addition, the number of hits for HCT indicates the species diversity available in the database for each order. 


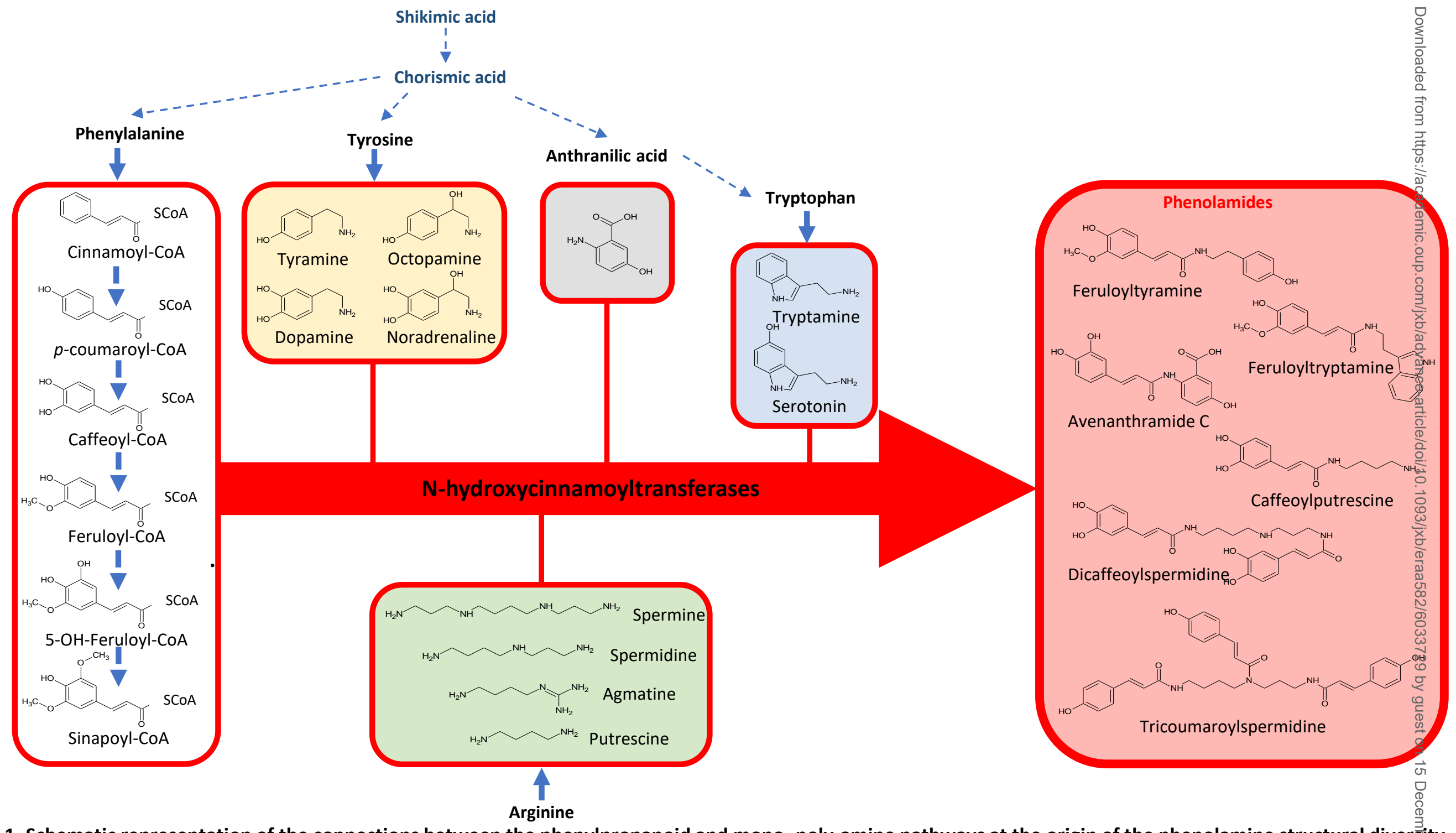

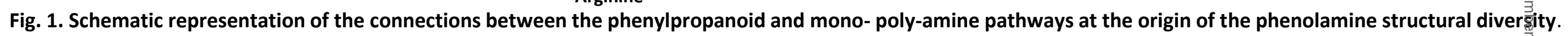
The six main phenolic acids are represented as CoA esters. The major mono- and polyamines are described together with their amino acid precursors. The final enzymatic్ step leading to the phenolamine biosynthesis is supported by $\mathrm{N}$-hydroxycinnamoyltransferases harboring specificity toward the amine moieties. 


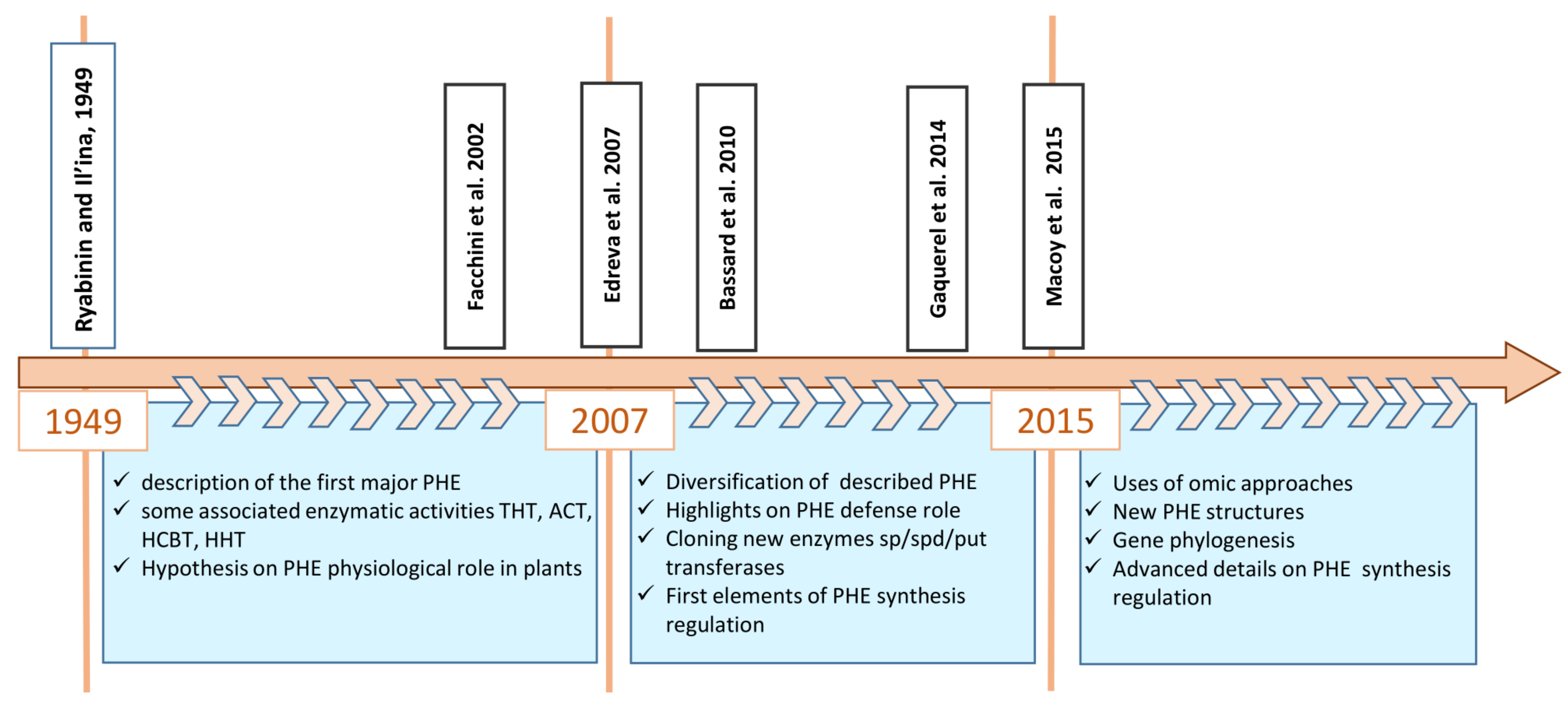




\section{Herbivory}

[RdR1

DLC3/DLC4

AGO8]

Multiple step $\stackrel{\lambda}{\rightarrow}$

regulations

\section{Pathogen}

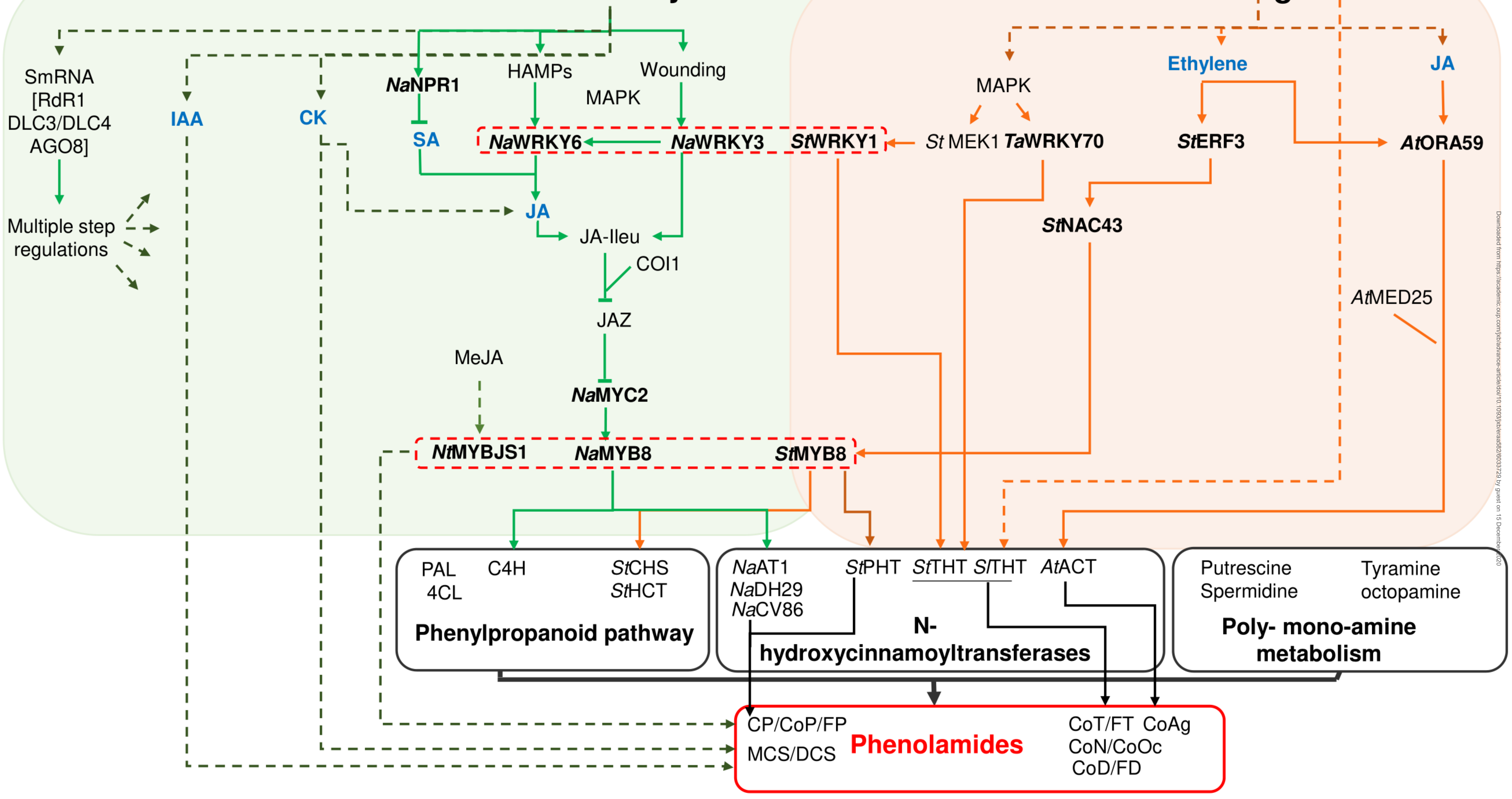




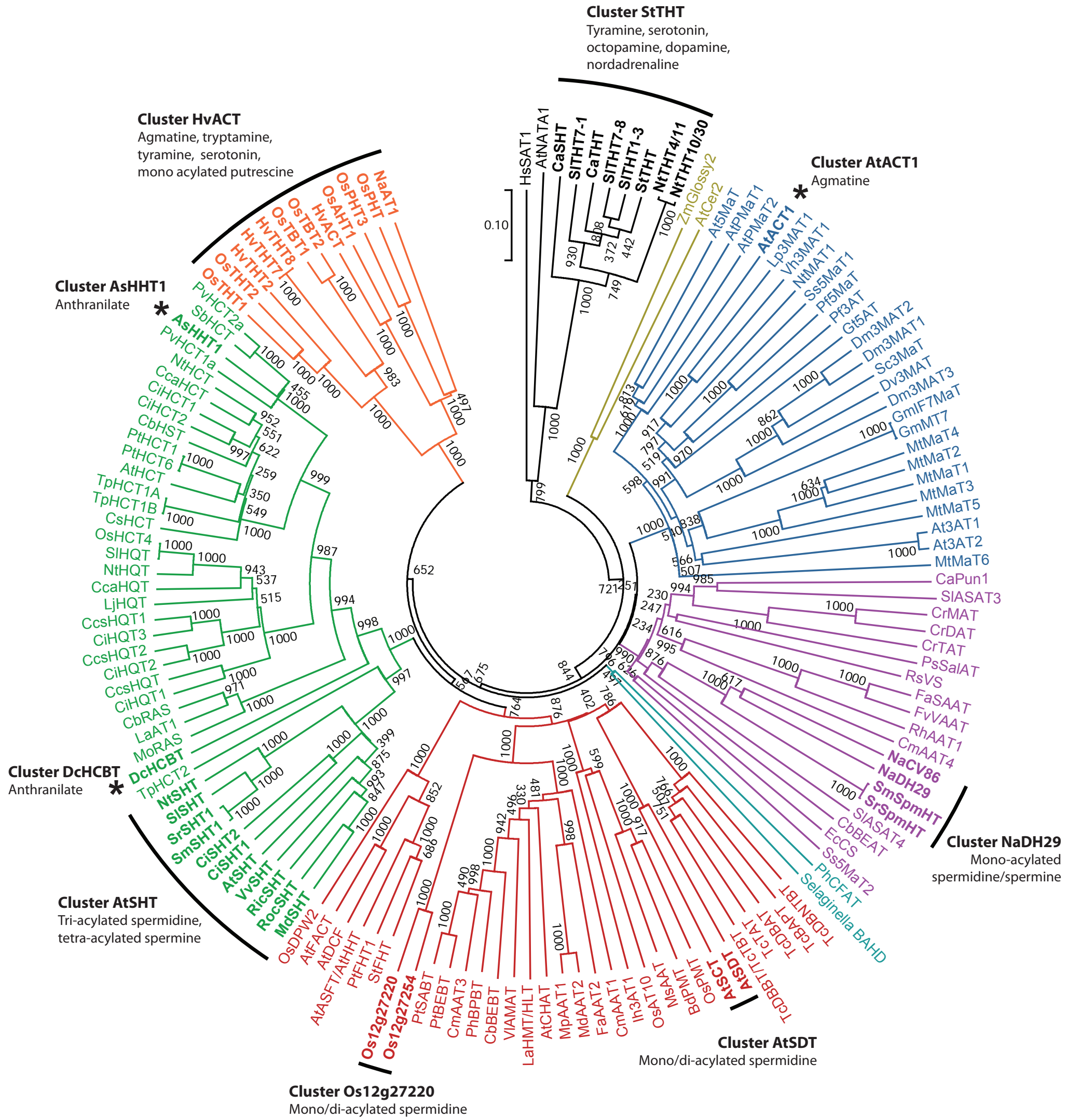


N-hydroxycinnamoyltransferase clusters

\begin{tabular}{|c|c|c|c|c|c|c|c|c|c|c|}
\hline & \multirow{3}{*}{$\begin{array}{l}\text { AtHCT } \\
700 \mathrm{seq}\end{array}$} & \multicolumn{9}{|c|}{$\mathrm{N}$-hydroxycinnamoyltransferase clusters } \\
\hline & & HvACT & SHT & AtSDT & Os12g27220 & AsHHT1 & AtACT1 & HCBT & StTHT & $\mathrm{NaDH} 29$ \\
\hline & & $793 \mathrm{seq}$ & 276 seq & 368 seq & $168 \mathrm{seq}$ & $1 \mathrm{seq}$ & 134 seq & 24 seq & 121 seq & 100 seq \\
\hline \multicolumn{11}{|l|}{ Tracheophyta } \\
\hline \multicolumn{11}{|l|}{ - Lycopodiopsida } \\
\hline L Selaginellales & 125 & 19 & & & & & & & & \\
\hline \multicolumn{11}{|l|}{ Luphyllophyyta } \\
\hline L Polypodiales & 16 & 2 & & & & & & & & \\
\hline \multicolumn{2}{|l|}{-Acrogymnospermae } & & & & & & & & & \\
\hline L_Pinales & 31 & 1 & & & & & & & & \\
\hline \multicolumn{11}{|l|}{$\begin{array}{l}\text { Lngiospermae } \\
L_{\text {Basal angiosperms }}\end{array}$} \\
\hline Amborellales & 37 & 22 & & & & & & & & \\
\hline Nymphaeales & 45 & 45 & & & & & & & & \\
\hline \multicolumn{2}{|l|}{-Magnoliids } & & & & & & & & & \\
\hline L_Laurales & 29 & 14 & & & & & & & & \\
\hline \multicolumn{11}{|l|}{-Monocots } \\
\hline F Alismatales & 44 & 6 & & & & & & & & \\
\hline Asparagales & 64 & 11 & & & & & & & & \\
\hline 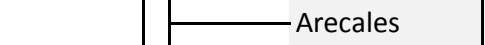 & 35 & 9 & & & 1 & & & & & \\
\hline 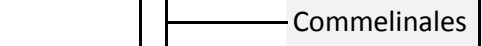 & & 45 & & & & & & & & \\
\hline 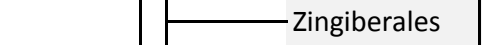 & 102 & & & & & & & & & \\
\hline Poales & 1225 & 670 & & & 244 & 1 & & & & \\
\hline \multicolumn{11}{|l|}{ Eudicots } \\
\hline F Proteales & 26 & 1 & & & & & & & & \\
\hline Ranunculales & 226 & 82 & & 3 & & & & & & \\
\hline \multicolumn{10}{|l|}{ Coreeudicots } & - Superrosids \\
\hline L Saxifragales & 1 & & & & & & & & & \\
\hline \multicolumn{11}{|l|}{ Losids } \\
\hline — Vitales & 79 & & 6 & 6 & & & & & & \\
\hline \multicolumn{11}{|l|}{ - Fabids } \\
\hline - Cucurbitales & 80 & & & & & & & & & \\
\hline -Fabales & 896 & 2 & 63 & 163 & & & & & & \\
\hline Fagales & 125 & 6 & 12 & 7 & & & & & & \\
\hline - Malpighiales & 391 & 51 & 17 & 16 & & & & & & \\
\hline L Rosales & 508 & 10 & 88 & 50 & & & & & & \\
\hline L Malvids & & & & & & & & & & \\
\hline - Brassicales & 405 & 53 & 52 & 213 & & & 167 & & & \\
\hline - Malvales & 737 & 36 & & 36 & & & & & & \\
\hline - Myrtales & 201 & 14 & 11 & & & & & & & \\
\hline LSapindales & 161 & & 9 & 2 & & & & & & \\
\hline L Superasterids & & & & & & & & & & \\
\hline —Caryophyllales & 117 & 1 & 3 & & & & & 35 & & \\
\hline Lsterids & & & & & & & & & & \\
\hline - Cornales & 21 & & 1 & 1 & & & & & & \\
\hline Ericales & 135 & 15 & 9 & 6 & & & & & & \\
\hline - Lamiids & & & & & & & & & & \\
\hline -Gentianales & 94 & 18 & & 4 & & & & & & \\
\hline - Lamiales & 209 & 41 & 15 & & & & & & & \\
\hline LSolanales & 234 & 82 & 27 & 2 & & & & & 134 & 120 \\
\hline Lampanulids & & & & & & & & & & \\
\hline -Apiales & 36 & & & & & & & & & \\
\hline - Asterales & 241 & 41 & 25 & & & & & & & \\
\hline L Dipsacales & 15 & 4 & & & & & & & & \\
\hline
\end{tabular}

